University of South Florida

DIGITAL COMMONS Digital Commons @ University of @ UNIVERSITY OF SOUTH FLORIDA South Florida

$12-1-2001$

\title{
Evaluation of First-Year Florida MPO Transit Capacity and Quality of Service Reports
}

CUTR

Follow this and additional works at: https://digitalcommons.usf.edu/cutr_nctr

\section{Scholar Commons Citation}

CUTR, "Evaluation of First-Year Florida MPO Transit Capacity and Quality of Service Reports" (2001). Research Reports. 212.

https://digitalcommons.usf.edu/cutr_nctr/212

This Technical Report is brought to you for free and open access by the National Center for Transit Research (NCTR) Archive (2000-2020) at Digital Commons @ University of South Florida. It has been accepted for inclusion in Research Reports by an authorized administrator of Digital Commons @ University of South Florida. For more information, please contact digitalcommons@usf.edu. 


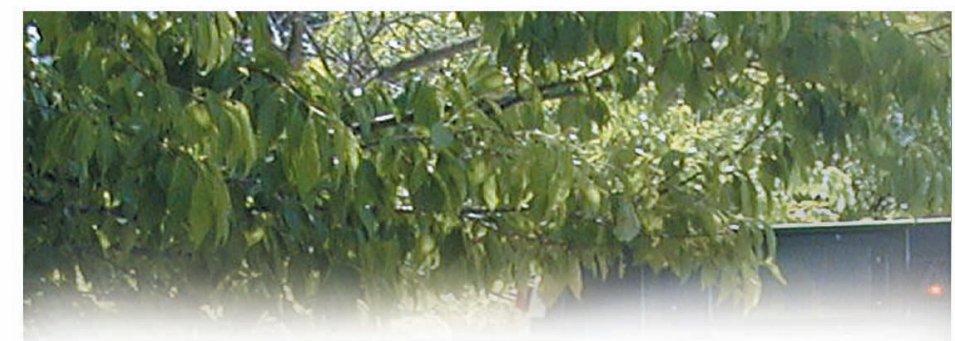

Evaluation of First-Year Florida MPO

Transit Capacity and Quality of Service Reports

December 2001

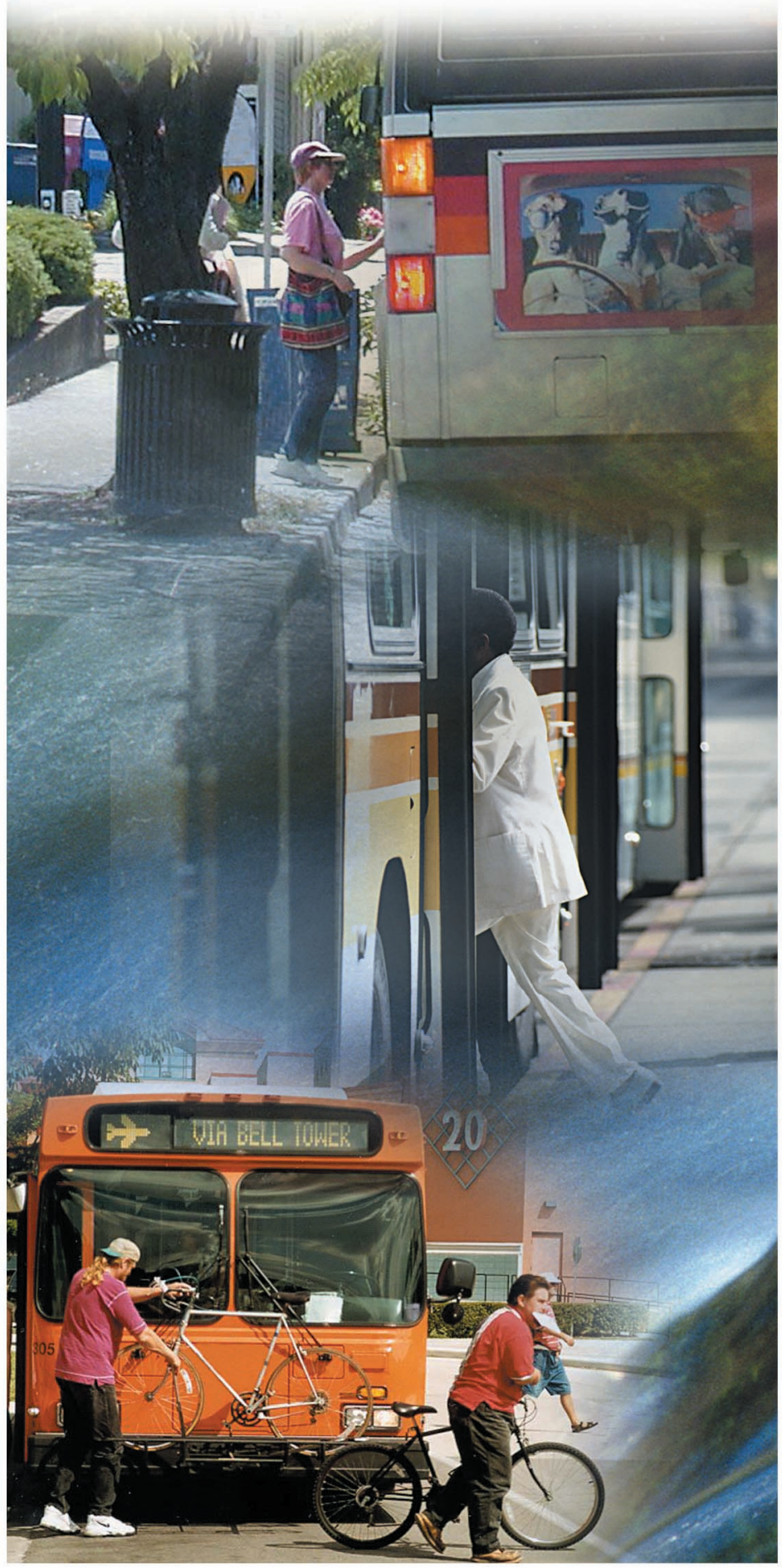




\begin{tabular}{|c|c|c|c|}
\hline $\begin{array}{l}\text { 1. Report No. } \\
\text { NCTR }-473-02\end{array}$ & 2. Government Accession No. & \multicolumn{2}{|c|}{ 3. Recipient's Catalog No. } \\
\hline \multirow{2}{*}{\multicolumn{2}{|c|}{$\begin{array}{l}\text { 4. Title and Subtitle } \\
\text { Evaluation of First-Year Florida MPO Transit Capacity and } \\
\text { Quality of Service Reports }\end{array}$}} & \multicolumn{2}{|c|}{$\begin{array}{l}\text { 5. Report Date } \\
\text { December } 2001\end{array}$} \\
\hline & & \multicolumn{2}{|c|}{ 6. Performing Organization Code } \\
\hline \multicolumn{2}{|c|}{$\begin{array}{l}\text { 7. Author(s) } \\
\text { Perk, Victoria; Thompson, Brenda; and Foreman, Chandra }\end{array}$} & \multicolumn{2}{|c|}{ 8. Performing Organization Report No. } \\
\hline \multirow{2}{*}{\multicolumn{2}{|c|}{$\begin{array}{l}\text { 9. Performing Organization Name and Address } \\
\text { National Center For Transit Research (NCTR) } \\
\text { University of South Florida CUT } 100 \\
4202 \text { East Fowler Avenue, Tampa, FL } 33620\end{array}$}} & \multicolumn{2}{|l|}{ 10. Work Unit No. } \\
\hline & & \multicolumn{2}{|c|}{$\begin{array}{l}\text { 11. Contract or Grant No. } \\
\text { DTRS98-G-0032 }\end{array}$} \\
\hline \multirow{2}{*}{\multicolumn{2}{|c|}{$\begin{array}{l}\text { 12. Sponsoring Agency Name and Address } \\
\text { Office of Research and Special Programs } \\
\text { U.S. Department of Transportation } \\
\text { Washington, DC } 20590 \\
\text { Florida } 32399\end{array}$}} & \multicolumn{2}{|c|}{ 13. Type of Report and Period Covered } \\
\hline & & \multicolumn{2}{|c|}{ 14. Sponsoring Agency Code } \\
\hline \multicolumn{4}{|c|}{$\begin{array}{l}\text { 15. Supplementary Notes } \\
\text { Supported by a Grant from the USDOT Research and Special Programs Administration, and the } \\
\text { Florida Department of Transportation }\end{array}$} \\
\hline \multicolumn{4}{|c|}{$\begin{array}{l}\text { 16. Abstract } \\
\text { As an application of the transit quality of service framework presented in the First Edition of the } \\
\text { Transit Capacity and Quality of Service Manual (TCQSM), the Florida Department of } \\
\text { Transportation (FDOT) required all MPOs in the state where fixed-route service operates to } \\
\text { analyze those services based on the six measures identified in the TCQSM: service frequency, } \\
\text { hours of service, service coverage, passenger loading, reliability (on-time performance/headway } \\
\text { adherence), and transit versus auto travel time. This first-year evaluation compiles the analyses } \\
\text { provided by the participating MPOs and provides an assessment of the performance of the transit } \\
\text { systems. In addition, the process used by the MPOs and transit systems to evaluate their services } \\
\text { is evaluated, and possible refinements to the process are suggested for future years based on the } \\
\text { first-time experiences of the MPOs. This evaluation serves as a model for other areas in the } \\
\text { country interested in applying the customer-oriented assessment of transit based on the TCQSM. }\end{array}$} \\
\hline $\begin{array}{l}\text { 17. Key Words } \\
\text { Public transit, MPO, } \\
\text { performance evaluation, transit } \\
\text { capacity and quality of service }\end{array}$ & $\begin{array}{l}\text { 18. Distribution Statement } \\
\text { Available to the public thro } \\
\text { Information Service (NTIS } \\
\text { VA } 22161,(703) 487-4650 \\
\text { the NCTR web site at http: }\end{array}$ & $\begin{array}{l}\text { the Natio } \\
85 \text { Port R } \\
\text { p://www.n } \\
\text { vw.nctr.us }\end{array}$ & $\begin{array}{l}\text { ical } \\
\text { ind through }\end{array}$ \\
\hline $\begin{array}{l}\text { 19. Security Classif. (of this report) } \\
\text { Unclassified }\end{array}$ & $\begin{array}{l}\text { 20. Security Classif. (of this page) } \\
\text { Unclassified }\end{array}$ & $\begin{array}{l}\text { 21. No. of pages } \\
45\end{array}$ & 22. Price \\
\hline
\end{tabular}




\section{EVALUATION OF FIRST-YEAR MPO TRANSIT CAPACITY AND QUALITY OF SERVICE REPORTS}

Final Report

December 2001 

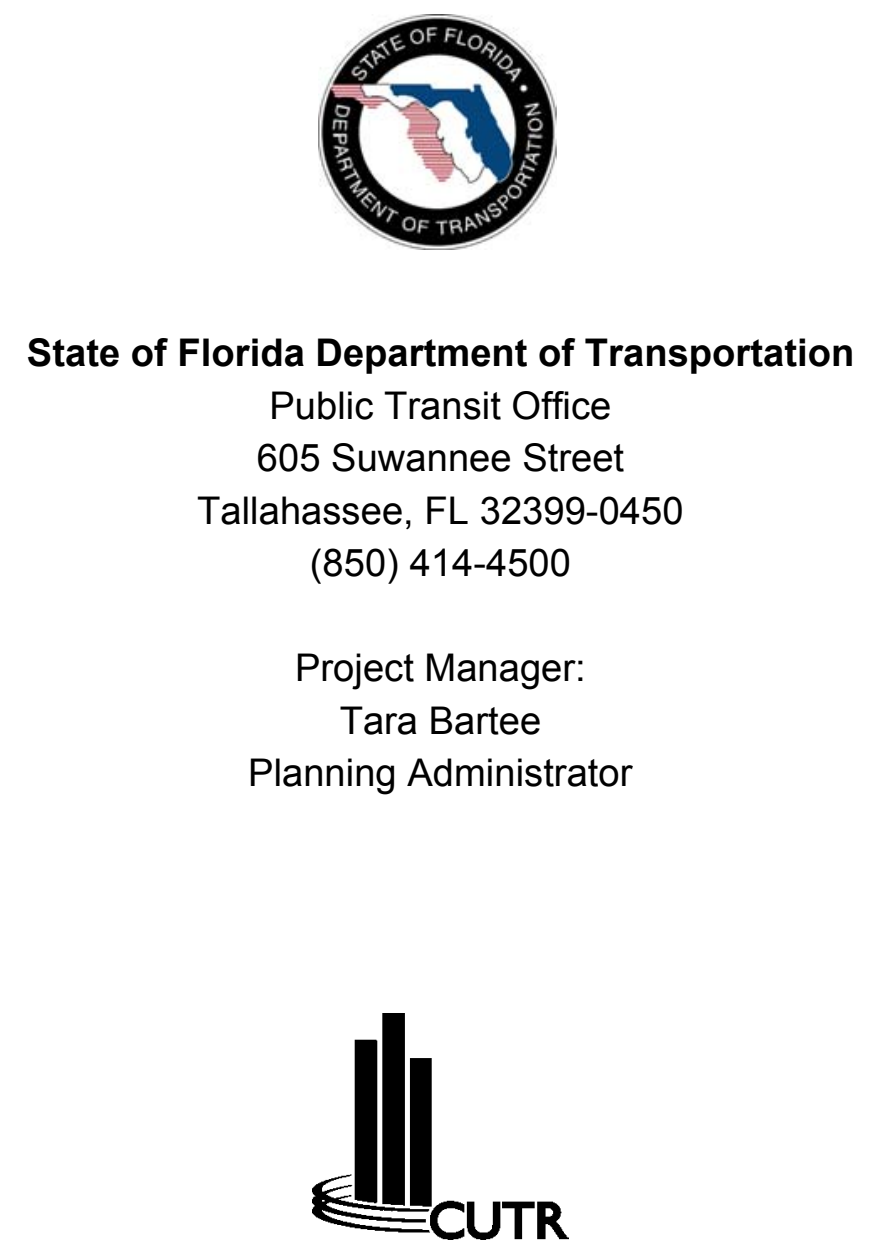

\author{
National Center for Transit Research \\ Center for Urban Transportation Research \\ University of South Florida \\ 4202 E. Fowler Avenue, CUT 100 \\ Tampa, FL 33620-5375
}

(813) 974-3120

Project Director: Dennis Hinebaugh, Transit Program Director

Project Manager: $\quad$ Victoria A. Perk, Research Associate

Project Staff: $\quad$ Brenda J. Thompson, Research Associate

Chandra Foreman, Research Associate

The opinions, findings and conclusions expressed in this publication are those of the authors and not necessarily those of the U.S. Department of Transportation or the State of Florida Department of Transportation. 
TABLE OF CONTENTS

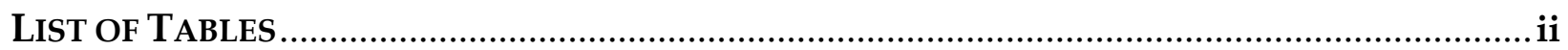

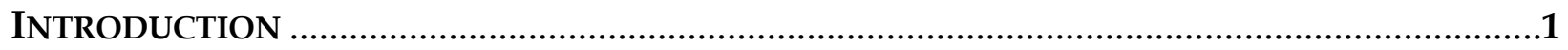

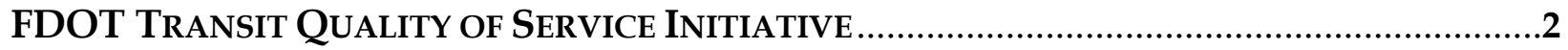

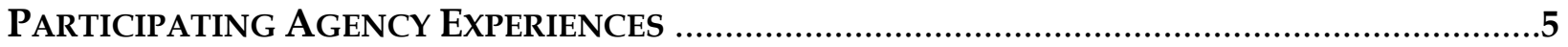

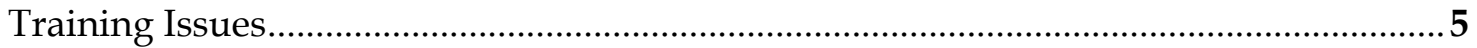

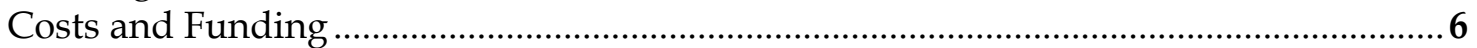

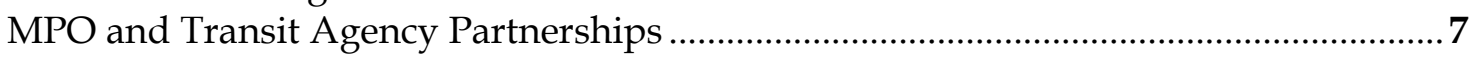

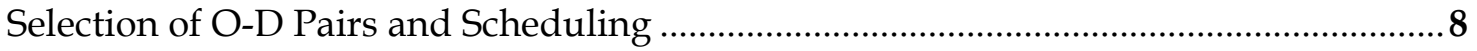

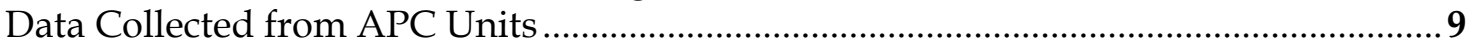

Time of Year, Window of Time, and Collection Days .................................................... 9

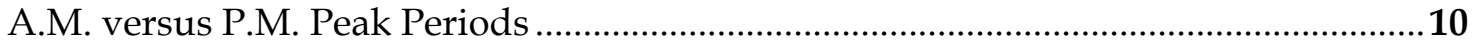

Route Evaluation versus Trip Evaluation................................................................11

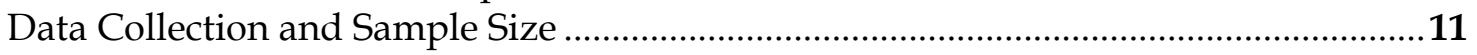

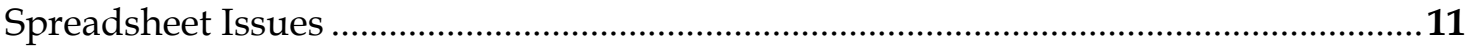

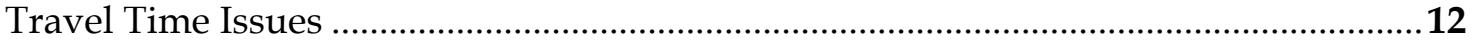

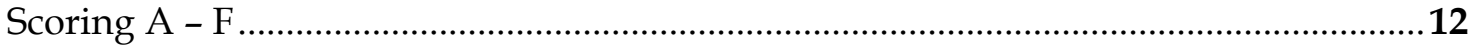

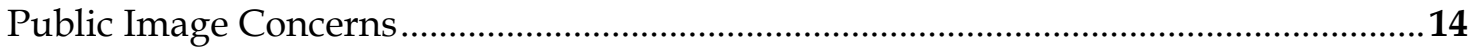

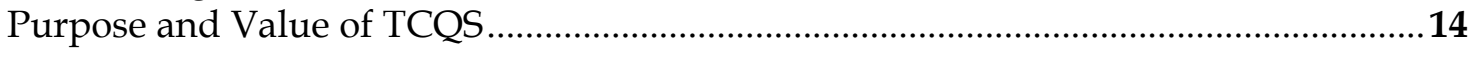

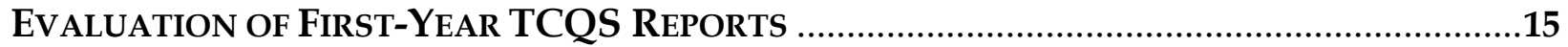

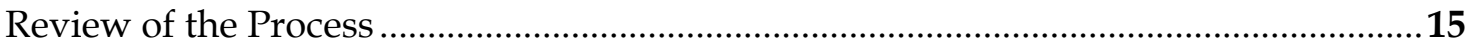

Review of the Statewide Results ...............................................................................19

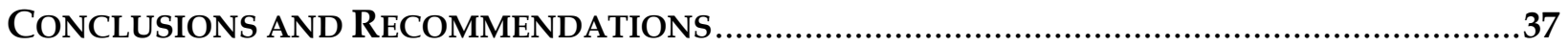




\section{LIST OF TABLES}

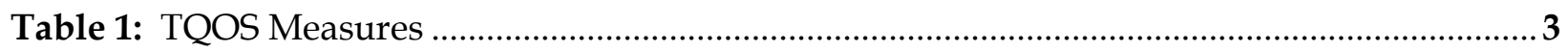

Table 2: Transit Systems with Fewer than 50 Peak Vehicles - Small Systems..............................19

Table 3: Transit Systems with 50 Peak Vehicles or Greater - Large Systems ............................... 20

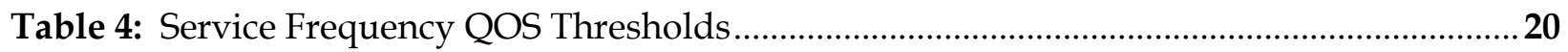

Table 5: Service Frequency QOS - Statewide ......................................................................... 21

Table 6: Service Frequency QOS Results - Small Systems …….................................................22

Table 7: Service Frequency QOS Results - Large Systems .......................................................... 22

Table 8: Hours of Service QOS Thresholds................................................................................... 23

Table 9: Hours of Service QOS Results - Statewide .....................................................................24

Table 10: Hours of Service QOS Results - Small Systems .........................................................25

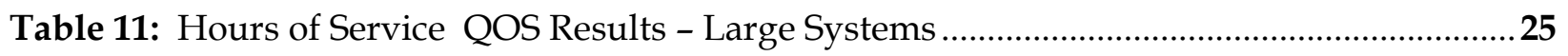

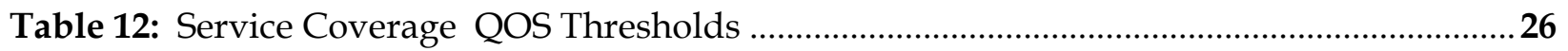

Table 13: Service Coverage QOS Results - Statewide .............................................................27

Table 14: Service Coverage QOS Results - Small Systems ..........................................................27

Table 15: Service Coverage QOS Results - Large Systems ...........................................................28

Table 16: Passenger Loading QOS Thresholds.............................................................................28

Table 17: Passenger Loading QOS Results - Statewide ................................................................29

Table 18: Passenger Loading QOS Results - Small Systems ............................................................30

Table 19: Passenger Loading QOS Results - large Systems .......................................................... 30

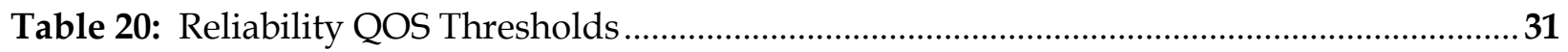

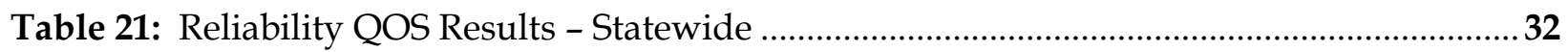

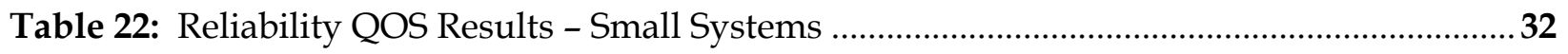

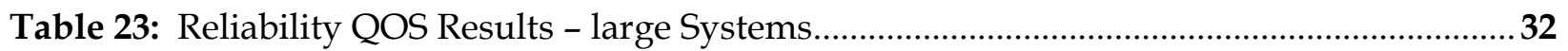

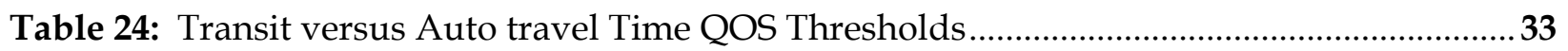

Table 25: Transit versus Auto travel Time QOS Results - Statewide .............................................34

Table 26: Transit versus Auto travel Time QOS Results - Small Systems ....................................34

Table 27: Transit versus Auto travel Time QOS Results - Large Systems ....................................35

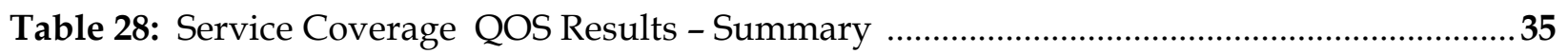

Table 29: TCQS Results - Summary of All O-D Pairs, Service Frequency,

Hours of Service, and Travel Time QOS..................................................................... 36

Table 30: TCQS Results - Summary of Top 15 O-D Pairs, Service Frequency,

Hours of Service, and Travel Time QOS..................................................................... 36

Table 31: TCQS Results - Summary of Top 15 O-D Pairs, Passenger Loading and Reliability QOS. 36 


\section{EVALUATION OF FIRST-YEAR FLORIDA MPO TRANSIT CAPACITY AND QUALITY OF SERVICE REPORTS}

\section{INTRODUCTION}

The Florida Department of Transportation (FDOT) is interested in the application of the new transit quality of service framework as presented in the First Edition of the Transit Capacity and Quality of Service Manual (TCQSM). This framework is seen as a tool to augment systematic evaluation of transit systems performed by FDOT. The goal is to provide a benchmark evaluation of transit systems within a specific time period such that the performance of the systems can be assessed from the transit users' point of view. FDOT required that the Florida Metropolitan Planning Organizations (MPOs) where fixed-route transit service operates coordinate an effort to evaluate those services within their respective regions with respect to the six transit service measures identified in the TCQSM.

This project, an evaluation of these first-year Florida MPO transit capacity and quality of service (TCQS) reports, involved the collection, compilation, and analysis of these reports as gathered from the MPOs. The reports were examined to make preliminary assessments of the overall performance of the transit systems in the state in terms of these new measures. While individual system results are not presented in this report, the six Transit Capacity and Quality of Service (TQOS) measures are presented in aggregate form for the state as a whole.

More than a general analysis and presentation of the results is contained in this report; this project also sought to evaluate the process undertaken by the transit systems and MPOs in completing this effort. It is understood that the results, i.e., the values of the six TCQS measures for the transit systems, from this first-time endeavor might not be as meaningful as results obtained in future attempts. This process is new for everyone involved and several issues arose involving the reporting instructions, methodologies, and time frames for analysis, all of which are discussed in this report, which impeded the achievement of optimal results for most agencies. It is FDOT's intention to discover and implement the data collection and reporting methodologies that will lead to the best and most valid TCQS results with the minimum effort on the part of the participating transit systems and MPOs. Any problems or inconsistencies found in gathering and reporting the required data are summarized in this report. Possible remedies and improvements to the process for subsequent years, based on the experiences of this first year, are also provided in the form of a series of recommendations. 
The purpose of the TCQS measures is to establish a means of evaluating the quality of transit service, from the users' perspective, that can be comparable to the level of service measures used for roadways, which are also designed from the perspective of the user (i.e., level of congestion). It is the hope of FDOT that the routine implementation of this procedure in the future will lead to increased investment in transit services throughout the state by prompting the allocation of resources toward the improvement of transit services with poor TCQS measures, similar to the response when roadways are deemed to perform poorly. This is the first known statewide use of this new customer-oriented transit performance evaluation procedure, and the results of this project will be beneficial to other DOTs, MPOs, and transit systems throughout the country that may be interested in the application of the performance measures found in the TCQSM.

The following section of this report contains background information on the six transit quality of service measures found in the TCQSM and the evaluation process itself. Then, the statewide TCQS results from the first-year effort, in terms of these measures, are presented in detail. Another section identifies problems and difficulties that were encountered in this first-year process based on the experiences of the participating agencies. Finally, recommendations are included that suggest remedies, refinements, and improvements to the process so that, in the future, the most beneficial and robust results will be obtained for the state.

\section{FDOT TRANSIT QUALITY OF SERVICE INITIATIVE}

FDOT required, as part of the FY 2000-2001 Florida State Planning Emphasis Area, that Florida MPOs where fixed-route transit exists organize an effort to evaluate those fixed-route services in terms of the six transit quality of service measures in the TCQSM. The evaluation was to be incorporated into each MPO's FY 2000-2001 Technical Work Program.

The six transit quality of service (TQOS) measures evaluated are:

- service coverage;

- service frequency;

- hours of service;

- transit travel time versus auto travel time;

- passenger loading; and

- reliability (on-time performance or headway adherence). 
The TQOS framework, as presented in the First Edition of the TCQSM, focuses on transit service availability and comfort and convenience from the users' point of view and culminates in the six measures previously listed. The first three measures, service coverage, service frequency, and hours of service, relate to the availability of transit service to the user. The measures of travel time (transit versus auto), passenger loading, and reliability are associated with the comfort and convenience to the transit user.

Each of the six TQOS measures is expressed on a scale from " $\mathrm{A}$ " to " $\mathrm{F}$," similar to roadway level of service measures, with " $\mathrm{A}$ " denoting the best quality of service and " $\mathrm{F}$ " representing the worst quality of service. Table 1 gives a brief description of the definitions of the measures. Further detail is provided later in this report.

Table 1: TQOS Measures

\begin{tabular}{|l|l|}
\hline \multicolumn{1}{|c|}{ Measure } & \multicolumn{1}{c|}{ Definition } \\
\hline Service Coverage & percent of transit-supportive area served \\
\hline Service Frequency & headway, in minutes \\
\hline Hours of Service & hours transit service is available per day \\
\hline Travel Time (transit vs. auto) & $\begin{array}{l}\text { travel time difference, in minutes, between transit and } \\
\text { auto for the same O-D pair }\end{array}$ \\
\hline Passenger Loading & degree of vehicle crowding; space available per passenger \\
\hline Reliability & comparison of actual versus scheduled arrival times \\
\hline
\end{tabular}

Each measure, except service coverage, was to be applied on a typical weekday p.m. peak period. Service coverage was evaluated for the typical weekday. A typical weekday was defined as Tuesday, Wednesday, or Thursday, and the p.m. peak period was defined from 4:00 p.m. to 6:00 p.m. The p.m. peak was chosen to mirror the p.m. peak period analysis procedures identified in FDOT's Level of Service Handbook for highways. The TCQS evaluations were to be conducted in March 2001, with a final report from each MPO area due to FDOT by July 1, 2001.

The evaluation process began with the selection of major activity centers in each study area. Large areas with populations of 200,000 or more were to select at least 10 activity centers, while smaller areas with populations of less than 200,000 were to select at least six activity centers. These major activity centers were to contain a balance of trip origins and destinations (although, as discussed later in this report, many more destinations than origins were ultimately selected, which may have impacted these first-year results) and were not to be locations necessarily best served by transit nor best served by automobile. The objective was to choose activity centers where demand is high for people in the community to travel to and travel from. Guidelines were provided for the areas to aid in the selection of the activity centers. Once the activity 
centers were chosen, trip pairs were developed from each activity center to all the other activity centers, thus producing at least 90 origin-destination (O-D) trips pairs for the large areas and at least $30 \mathrm{O}-\mathrm{D}$ pairs for the small areas. It was necessary to collect additional information on the O-D pairs to assist with the calculation of the TQOS measures. From the local travel demand model, total trip demand (auto and transit), measured in trips per hour, was generated for each O-D pair. In addition, the fastest route, or combination of routes, that connect each O-D pair during the weekday p.m. period was determined, as was the number of opportunities to travel per hour from the given origin to the given destination.

The measures for Service Frequency Quality of Service (QOS), Hours of Service QOS, and transit travel times (for use in the Travel Time QOS measure) were developed using existing transit route maps and schedules produced by the individual transit systems for the public. Auto travel times, necessary to complete the process for calculating the Travel Time QOS measure, were derived from the local travel demand model.

Passenger loading and reliability data were required to be measured for only the 15 O-D pairs with the highest travel demands based on travel demand model results. Measurements on these trip pairs were to be made at the maximum load point for trips departing the origin between 4:00 p.m. and 6:00 p.m. If a passenger would need to transfer from one transit route to another to complete the trip, data were collected for only the first leg of the trip. Reliability information was to be recorded using the arrival time of the vehicle at the maximum load point. Passenger Loading QOS was calculated using Automatic Passenger Counter (APC) data for two transit systems, while all others used field measurements. Reliability QOS could be calculated using Automatic Vehicle Location (AVL) data, but all participating systems in this endeavor, except two, used field measurements. For both passenger loading and reliability, either 10 observations or three days of peak observations should have been made, whichever is greater.

Service Coverage QOS most easily could be determined by utilizing GIS technology. However, if GIS software was not available to an area, a manual method, described in the Agency Reporting Guide, could be applied. Two of the participants in this evaluation utilized the manual technique for measuring service coverage. Data on population, households, and employment was needed by geographical unit such as Traffic Analysis Zone (TAZ) or census block group. Transit stop or route location was also necessary. While the reporting agencies were to indicate the type of data used and the year that the data represented, there was no specification as to exactly which data or which year should be used. This makes sense, since various areas around the state may have different types of data more easily available or more recent than others. However, the various data used by the participating agencies did not 
facilitate a consistent aggregation of the Service Coverage QOS for the state as a whole. This issue is discussed further later in this report.

Florida MPOs and transit systems that were to participate in this effort received a comprehensive Agency Reporting Guide prepared by Kittelson \& Associates, Inc., for FDOT. In addition, three training courses were held in November 2000, prior to the start of the evaluation in March 2001. The Agency Reporting Guide included detailed instructions on how to use the provided "Transit QOS Reporting Worksheet" prepared in Microsoft Excel format. In addition to completing the information in the evaluation spreadsheets, each participating MPO was to provide a brief written report summarizing the process and results in their respective areas. While all data collection was to occur in March 2001, the MPOs' individual reports were due to FDOT no later than July 1, 2001. Kittelson and FDOT staff made themselves available to assist participating agencies throughout the process.

\section{Participating AgenCy EXPerienCes}

As part of the evaluation of the first-year Florida TCQS Reports, CUTR contacted representatives from each of the participating agencies, including appropriate MPO and transit system staff, to obtain a review of each individual area's experience with this process of measuring transit quality of service. The discussion guide that was used for these informal interviews is included in Appendix A of this report. For each MPO that conducted the TCQS process, CUTR was able to contact at least one transit system representative and an MPO representative. In areas that used a consulting firm to perform the analysis, CUTR was able, in a few cases, to speak with a consultant who was directly involved in the process.

Since this was the first time that the MPOs and transit systems applied the process from the TCQSM in evaluating their fixed-route services, inevitably there were problems, difficulties, questions, and other issues that arose during the process of collecting and reporting the required data. The informal telephone interviews that were conducted with representatives of the participating agencies are summarized herein.

\section{Training Issues}

FDOT provided educational TCQS resources to the MPOs and transit agencies. As discussed previously, training classes were offered before the TCQS initiative began. Transit planners, MPOs, and consultants were invited to attend one of the three classes offered. Those who attended believe that the class was indeed helpful. Some planners were not able to attend one of the scheduled training courses. They cited other commitments, not enough advance notice of 
the class by FDOT, and long travel distances as the reasons for not participating. Hence, these representatives had to rely on the written material for guidance.

An Agency Reporting Guide was distributed to provide additional insight. Five agencies reported that they had some difficulties utilizing the guide. These individuals concluded that the guide was difficult to follow and not as informative as it needed to be. For instance, according to an agency planner who was not able to attend one of the classes, "A training course may have given me another perspective. I just used the manual. I didn't understand why we had to collect certain data." Another said, "The directions in the manual were not simple to follow; I had to search for definitions and directions." Finally, some had specific issues related to their system's operations.

During the actual collection and reporting process, some questions arose that were not addressed in either the training class or the Agency Reporting Guide. If questions arose, most relied on FDOT for advice. Although all seemed pleased with the correspondence from FDOT, a few representatives from transit systems were disappointed with the technical assistance offered.

\section{Costs and Funding}

The costs of undertaking the TCQS evaluation depended upon several factors, including transit system size. The participants cited a range of costs from $\$ 3,900$ to $\$ 50,000$. One system, which was able to utilize data from APCs and did not hire an outside consultant, reported the costs as "negligible." Costs included travel to training classes, labor, consultant costs, and materials. Labor to collect data was the largest expense reported. Consequently, systems that were able to use volunteers, bus drivers, or temporary employees to survey trips could substantially lower their costs. Usually, the more modes a transit system had to survey, the more costly the project. In particular, surveying a heavy rail mode was the most costly since all passengers had to be counted on board six cars in 40 seconds. Hence, labor costs rose as transit system size increased. Also, systems that had a major activity center, such as a mall, near a transfer center or super stop encountered a cost savings since data for several trips could usually be collected at one time.

Transit systems utilized a variety of labor options for surveying. To keep costs lower, transit agencies employed volunteers, such as Boy Scout troops, employees' children, and interns. Also, four transit agencies depended upon bus drivers to collect ridership and on-time performance data. Consultants were used by a few agencies. Many times the TCQS tasks were added to a prior contract between consultants or researchers and the transit system. Moreover, 
in-house labor was used, such as full-time planning staff members and agency management, to schedule trips, collect data, and report data. Two agencies stated that they used in-house labor for surveying tasks due to the fact that the bidding process was too time-consuming. These agencies reported that their costs increased because some mid-management employees received overtime compensation. In contrast, others used in-house staff because consultants and temporary employees were too costly. Those utilizing in-house staff mostly complained that other tasks were compromised, including National Transit Database (NTD) surveying, special projects, and day-to-day operational oversight.

\section{MPO and Transit Agency Partnerships}

For the most part, MPOs and transit agencies worked to complete the TCQS evaluation together. Usually, MPOs provided modeling and geographical analysis while transit agencies were in charge of surveying. In fact, one MPO representative stated that she "worked together with transit to get it done and actually enjoyed it." Another MPO participant discussed a problem in which "everybody was trying to pass the buck" during the beginning of the process. However, after communicating, they all resolved the issue. Also, an MPO participant related the need to be a "watchdog" over the transit agency to make sure they were reporting figures correctly. He monitored the effort by spot-checking and participating in the data collection process to ensure the legitimacy of the data.

A few transit agencies reported significant participation difficulties with their MPOs. According to one system, its MPO did not accept the responsibility of the report until the very end of the time frame available for this evaluation. The transit system representative was disappointed that the MPO never went to a training class even after several invitation letters, the MPO balked at running the local travel demand model, and the MPO did not begin to help until late March, when additional staffing was not crucial anymore. This transit agency also complained that the report was not as valuable as it could have been to get more funds from its commission since they are viewed as a biased party. This individual clearly did not understand that the goal is to only provide a statewide summary at this time-individual results may be used internally to look for areas of improvement, but it is not necessary to forward the report to any local governing body.

While there were a few instances of noncooperation between MPOs and transit systems, overall the two local entities worked well together. In some areas, MPO staff performed a larger share of the work involved, while in other areas the transit agencies shouldered the greater responsibility. It is anticipated that the division of tasks between the MPOs and transit systems will vary from area to area, depending upon the relationship between the two, staff interest, 
and staff expertise. However, FDOT intends for this to be an MPO effort and, as such, MPOs must be made well aware that the TCQS evaluation is primarily their responsibility.

\section{Selection of O-D Pairs and Scheduling}

Participants discussed the benefits of evaluating trips between activity center pairs. For instance, one consultant said, "The evaluation of trip pairs, while some might find it cumbersome, is probably the best way to go to achieve the purpose of this study." In addition, an MPO representative stated, "The selection of the activity centers is one of the most helpful parts of the study - not how good we can make the system look, but see if this tells us anything and what improvements can be made."

The selection of activity centers was usually not difficult, albeit some had improvement suggestions. The purpose of the selection process was to select activity centers based on where people are really traveling. However, it was mentioned that the selection process could be biased to make the system look good. If pairs are not selected based on the demand for the origins and destinations, interviewees believe that the data could hamper meaningful decisions. In contrast, if the selection was representative, interviewees stated the benefits of determining how well transit currently serves those demands.

The methodology to determine origin-destination pairs was discussed by a few participants. One small system related the difficulties they had with choosing 10 to $15 \mathrm{O}-\mathrm{D}$ pairs since they are located in a more rural area. In fact, two decided to change their method of selecting which O-D pairs would end up in the top 15 for sampling. Both discounted the use of collecting data on two-way trips. According to one of these participants, his methodology did not include twoway trips (i.e., both directions of travel for an O-D pair) because he "intuitively used traffic patterns to determine that the CBD to downtown is a stronger movement than the airport to downtown, consequently addressing evening peak period demand and opening up other movements that were examined in order to give a better distribution of trips." Also, a private consultant firm chose to survey the 15 highest travel demand O-D pairs between different activity centers, because the demand estimate from one activity center to one other was the same as in the opposite direction. Moreover, this consultant stated that there should be a balance of origins and destinations when selecting activity centers, including selecting residences as origins and all others as destinations. 


\section{Data Collected from APC Units}

Two transit systems were able to use APC data to acquire information. While one was able to just alter procedures already in place, the other had some difficulties due to the fact that their APC units were newly installed. The new automated counters malfunctioned, causing some passenger loading information to not make sense. Hence, an extension was necessary to obtain better data. Additional time was necessary to learn how to use APCs and extract meaningful data from them. Once familiar, this transit agency's representative believes that the process would be much smoother. Both transit systems saved substantial labor surveying costs by using APCs, albeit scheduling proved to be challenging for the interlined routes. Those vehicles that had the APC equipment had to be rearranged to make the randomly selected trips. Two weeks were needed to assign the appropriate bus (bus with APC) to the appropriate route for 10 units of 10 activity centers. Moreover, due to data extracting difficulties, both would like to collect data by route or month instead of by trip. Overall, APCs proved to be useful and efficient once employees were knowledgeable on how to use them.

\section{Time of Year, Window of Time, and Collection Days}

Participants were asked their preference for the time of year to conduct this evaluation. Two planners mentioned that the TCQS project should not be done annually due to their forecasts that the information will change in one year's time and that it will continue to be a financial burden. In contrast, three planners mentioned the need to sample during different seasons throughout the year. They described seasonal fluctuations that are not being captured in the current data collection process. Finally, ridership fluctuations occur during the month as well as between months. Hence, one participant believes a data collection system that considers that the beginning of the month usually has the highest ridership whereas the end of the month has the lowest would be practical.

Representatives considered workload (i.e., NTD reporting, special events), traffic patterns, and peak ridership seasons in order to determine their seasonal preferences. In fact, many of the planners determined ideal surveying months by their agency's ridership peaks. A system in northeastern Florida mentioned October because it was the transit agency's highest ridership month. May through June months were mentioned by systems in Florida's panhandle that experience peak ridership in the summer. In contrast, several planners specifically mentioned that surveying during the summer would not be best since ridership tends to drop, especially in July. February, March, or April was chosen by peninsular state transit systems to capture seasonal residents, students, and Spring Break visitors. In summary, seasonal ridership changes affect peak ridership figures so systems would like to choose a month that best suits their 
particular fluctuations. This methodology would be appropriate if the goal of the TCQS evaluation is to show an aggregate view of how transit systems perform in their peak season.

All but one of the transit agency representatives agreed that the time frame of one month was too short. The systems with hourly frequencies had the greatest difficulties in collecting the minimum number of samples, whereas those with high frequencies had the least. They cited agency coordination, interlining issues, scheduling difficulties, collection errors, special events, and labor shortages to be reasons to lengthen the period of time for collecting data. Some said that they were not able to survey all pairs in a week. Also, one stated the importance of gathering a larger sample size. Suggested time frames include 45 days to 12 weeks. Flexibility to choose the sampling weeks within a certain period of time also was suggested by a few transit system representatives.

Typically, the data collection days are Tuesday through Thursday. However, 10 of the interviewed planners would like to at least add Mondays for an additional survey day since three days of the week does not provide enough opportunity for them to evaluate pairs. Also, three participants from smaller systems mentioned that adding Fridays would be beneficial for them because those days are fairly typical in terms of weekday ridership and would not cause data discrepancies. Only two participants did not like the idea of adding additional collection days. They mentioned holiday and flex-time issues as well as consistency with the data collection procedures for auto travel.

\section{A.M. versus P.M. Peak Periods}

There was not a consensus among the respondents when asked for their preferable peak period. Although two would like to measure both a.m. and p.m. peaks, all other participants responded differently. One planner indicated that peaks measure professional worker traveling patterns rather than shift workers who may work unorthodox hours. Most preferred measuring during the a.m. peak because they believe it would produce better results since ridership is typically higher and more concentrated than in the p.m. peak. In fact, one planner stated that the p.m. peak period "would not be as conclusive because people tend to leave work at varying times and destinations typically vary due to errands." In addition, another system planner mentioned a.m. is better due to a higher amount of college student ridership. Finally, a few transit system representatives believe that their p.m. peak began at 3:00 p.m. and lasted as long as 7:00 p.m., and the sampling time frame is from 4:00 p.m. to 6:00 p.m. 


\section{Route Evaluation versus Trip Evaluation}

When asked whether the TCQS evaluation should focus on routes or O-D pairs, all but one of the transit agency respondents indicated that they would like to survey and report an entire route. These respondents suggested that evaluating routes would be easier to conduct, extract data, and report to constituents. In contrast, a consultant, an MPO representative, and a large transit authority respondent stated the need to collect trip information in order to find out whether transit meets the demands of where people want to go. As the consultant said, "So what if a route has good frequency and convenient hours of service if the route does not get people where they want and need to go. Trip evaluations will help agencies see what is important." Finally, a few other participants suggested that the maximum load point on the first leg of the trip (if a transfer was needed to complete a trip, only the first leg of the trip needed to be observed for the loading and reliability information) may not be the maximum load point for the whole trip. Hence, the "whole picture" cannot be seen if measurements are taken only on the first leg. One proposal to fix this problem included averaging the frequency and hour information for the routes involved in the trip and then taking the measurements on the route segment that does have the maximum load point, which may not be on the first leg.

\section{Data Collection and Sample Size}

Several transit planners would like to have the opportunity to use larger sample sizes. Citations of wasted resources were linked to the opinion that collecting the TCQS data via any small sample is unproductive. In fact, one planning organization decided that it would not calculate "achieved tolerance" due to the fact that it would be unreliable from the small required sample size. This organization also stated that these minimum sample sizes created limited usefulness and applicability of the resulting information. Hence, persons suggested integrating NTD and/or Transit Development Plan (TDP) data gathering programs as much as possible in the TCQS study.

\section{Spreadsheet Issues}

Five transit systems encountered problems with the spreadsheet file provided to the participants for this evaluation. Although data could easily be entered into the worksheets, a few minor changes were needed to correct formulas or add additional data rows. According to one of the consultants, "the worksheet formulas did not reference the correct cells in the trips worksheet or the cells that were referenced did not contain formulas." Additionally, a few of the worksheets did not print out correctly until the print area was changed. Another participant had error messages when the spreadsheet was not able to calculate an " $\mathrm{A}$ " - " $\mathrm{F}$ " 
score for a major activity center that does not have transit service. A consultant that helped to develop the spreadsheet would like to add a column to account for congestion in subsequent reviews. Also, the database management program, Transit Level of Service (TLOS), was not usable for a few of the larger transit systems' data sets. Finally, two agencies responded that the Microsoft Excel format was difficult to utilize in Lotus, rendering automated features of the parent Excel file useless. Consequently, a suggestion to use a stand-alone program, similar to ART-PLAN, was made.

\section{Travel Time Issues}

There were issues with the comparison of bus and automobile travel times. First, comparing transit travel time during the peak and average daily automobile travel time was deemed unfair since actual bus travel times should be evaluated relative to similarly congested conditions on area roadways. Complaints that theoretical automobile results were compared with field data included, "it is impossible to estimate and compare the number of trips that are made by automobile during the peak period since the FSUTMS model only reports daily travel demand between the TAZs." Also, bus travel times are based upon schedules while automobile trips are not, rendering an "apples and oranges" comparison because schedules do not take into account congestion. Accordingly, this comparison "makes results look worse when they were quite normal." Second, the routes taken by a bus from one activity center to another may not be the same route an automobile driver would use. Third, according to a few participants, FSUTMS understated auto travel time values. For instance, trips by auto during the peak were projected to be half the time it would realistically take and the seasonal adjustment factors were programmed to be too lenient for busy shopping districts and drawbridge allowances. Travel demand models are different from area to area and produce results in varying forms; this must be considered when evaluating the individual area results on an aggregate statewide basis.

\section{Scoring A-F}

All system representatives were disappointed with the failing grades they received, although the measures were not unexpected in most cases. They were rated on an alphabetical grading scale (A to $\mathrm{F}$ ) that is similar to the grading scale for roadways. This scoring system was too difficult to pass, according to a several transit planners. A few stated that their service is quality and meets the needs of their customers even though they received failing grades (Fs). In fact, one participant stated, "you have to be perfect to get a B or C on the evaluation." It is true that one aspect of transit service that is not addressed by the TCQS framework is the real uniqueness of each individual area and its transit service and whether the service on the streets is congruent with community goals for transit. 
On-time performance ratings often were mentioned to be unrealistic. They discussed many issues, including schedules that are not designed for peak service, recording arrival times rather than departure times, buses stuck in road congestion from poor highway LOS, and utilizing the times points in schedules rather than stops in between. Recommendations were given to alleviate some of these on-time performance grading issues. Since "everyone's five minutes late in the peak," there should be a longer on-time performance grace period. In fact, one transit planner stated that there should be a sliding scale. He thought that it was unfair that "30 minutes late counts the same as six minutes late" when "often a six-minute delay can be made up later in the run." In addition, many of the maximum load points occur at transfer centers, where many buses meet for timed transfers, and recovery time is often built into schedules at these transfer centers. However, if a bus arrived at a transfer center more than five minutes early but left on schedule, it was still considered to not be on-time according to the guidelines given for measuring on-time performance.

Other suggestions to enhance the TCQS scoring framework also were made. The issues encompassed a wide range of topics: seating capacity, transit-supportive areas, and unique route and service structures. One participant noted that a passenger's decision to ride would not be affected if he or she had to stand during a short trip, yet the scoring system for passenger loading does not seem to account for the fact that some might not mind standing for short trips. This individual also thought that riding a 12-square foot bus or a 6-square foot bus would not matter to his customers. A more suburban transit system declared that some of the standards, such as 24-hour service, were not applicable to its mostly elderly customers. Moreover, according to one planner, his system did not get credit for an area that is not transit-supportive by utilizing TAZs, but it would get credit if he measured using census tracts (although census tracts are, of course, larger units). Another stated that his system did not get credit for the service that exists in non-transit-supportive areas; however, this individual did not understand that the purpose of the service coverage information was to focus on coverage of transitsupportive areas only. Also, another system had difficulty choosing a TAZ when some activity centers encompassed many TAZs (i.e., one downtown consisted of $17 \mathrm{TAZs}$ ).

Agencies with unique routing and service structures encountered difficulties. Those agencies that have to service long but narrow geographical areas (i.e., 75 miles) had problems achieving high QOS measures. Service that included hub-and-spoke routing structures were hurt by the scoring system since transfers were needed to get from one activity center to another. Also, a system that serves the eastern and western parts of its county separately, except for one connector route, believes that it was misrepresented when comparing the commuter's park-andride activity centers in the western portion of the county to the activity centers near the beach on the eastern side that are utilized by tourists. Hence, comparing the activity centers in the 
east separately from the activity centers in the west would fit the transit customer patterns better. This system's MPO planner thought that an evaluation of the core service area only would be more representative.

\section{Public Image Concerns}

Three transit system representatives voiced significant public image concerns. They are concerned that once the report is generated at the local level, "any reporter can come in and ask to see it." Hence, the report is open to wrong interpretations by public leaders and the media. Realizing that the state's purpose is to aggregate the individual transit systems' data into statewide figures, these agencies are asking for help from the state to explain the purpose of the TCQS evaluation to pressuring public groups who may utilize the information incorrectly and, thereby, cause negative public opinion followed by less funding opportunities. One system did mention correspondence and useful guidance from FDOT when facing this issue. She also stated that in the upcoming training classes including information about handling requests for information may be useful to other system planners.

\section{Purpose and Value of TCQS}

Participants were asked their perception of the purpose and value of the TCQS effort. There were mixed sentiments. Two planners considered the comparison between auto and transit travel time to be useful. Moreover, according to one consulting firm, one of the most valuable parts of the evaluation was the infrastructure/amenities analysis. Many participants found the selection of activity centers to be a very useful endeavor that set the stage for measuring how well the existing transit services meet the travel demands of the area. These participants agreed that this process has the potential to provide results that would not only be useful to FDOT for its purposes but also to the individual area. Most agree that the state's purpose to gain transit attention and funding is good. However, many also stated that the current process is not very valuable since it is costly and not helpful to transit agencies. A common suggestion was to integrate the TDP and TCQS processes as much as possible.

Most transit system and MPO representatives complained that they already knew the outcomes of this project. Smaller systems emphasized that it took a lot of time and did not tell them anything new since they can tell what is going on from day to day and are able to make adjustments on a daily basis. Larger systems also complained that the report was not useful since it replicates surveying and evaluations that are already being done for other reasons, such as TDPs. Consultants argued that, while the evaluation quantified a lot of intuitive factors, the failures did not help to generate solutions and did not give direction for future transit services. 
It is important to note that these comments were collected before any of the participants had a chance to see the statewide results of this analysis. Most of those interviewed by CUTR for follow-up purposes had seen some of the initial results and had more positive reactions to this effort and its purpose.

\section{EVALUATION OF FIRST-YEAR TCQS REPORTS}

This section addresses the process undertaken by the participating agencies and also analyzes the resulting TQOS measures. CUTR collected and reviewed each of the reports submitted by the MPOs for the purpose of providing an overall assessment of how well the MPOs and transit systems conducted the evaluation. In addition, all of the data submitted by the MPOs and transit systems using the standardized electronic spreadsheets were compiled into a format that can be used in the development of a statewide report to provide an overall evaluation of the performance of Florida's transit systems based on the six TQOS measures.

\section{Review of the Process}

All but one of Florida's MPOs where fixed-route transit systems exist, and that were required to participate in this effort, did so and submitted a report to FDOT. This resulted in 17 MPO TCQS reports representing 18 fixed-route transit systems. All but six were received at FDOT by July 1, 2001. Three others were submitted later in July, and the remaining three were submitted after July. Each participating agency submitted a completed spreadsheet. While a few submitted only the completed spreadsheets, others who prepared additional written materials submitted items ranging from a simple letter or memorandum to detailed bound reports. The transit agencies represented in this evaluation are listed on the following page: 
- Broward County Transit

- Escambia County Area Transit

- Gainesville Regional Transit System

- Hillsborough Area Regional Transit Auth.

- Jacksonville Transportation Authority

- Lakeland Area Mass Transit District*

- Lee County Transit

- $\quad \operatorname{Lynx}$ (Central FL Regional Transit Auth.)

- Manatee County Area Transit**
- Miami-Dade Transit

- Ocala/Marion MPO (SunTran)

- Palm Beach County Transportation Agency

- Pasco County Public Transportation

- Sarasota County Area Transit**

- Space Coast Area Transit

- Tallahassee Transit

- Volusia County dba VOTRAN

- Winter Haven Area Transit*

* Lakeland's and Winter Haven's services were evaluated together by the Polk TPO.

** Manatee's and Sarasota's services were evaluated separately by the Sarasota-Manatee MPO.

All of the participating agencies selected at least the minimum number of activity centers. Five transit systems were evaluated using more than the minimum number of selected activity centers for their respective area populations. Although guidance was given to assist the areas in selecting major activity centers, the resulting choices were heavily represented by typical destinations (as opposed to typical origins).

Auto travel times between the O-D pairs were to be determined by local travel demand model output. As mentioned previously, several participants indicated that these travel times derived from FSUTMS were suspect. While some systems thought that the times were overstated, most believed they were significantly understated. The issue of comparability between the theoretically estimated auto travel times and the transit travel times recorded from actual transit schedules was a contentious one. In addition to the apparent "apples to oranges" comparisons, it was noted that FSUTMS measures the times between the centers of TAZs, while the transit times are calculated from point to point.

The compilation and reporting of the service frequency, hours of service, and transit travel time information for the O-D trip pairs was relatively straightforward, with the relevant information being readily available from published transit maps and schedules. Complications tended to arise with the collection of the loading and reliability data for the top $15 \mathrm{O}-\mathrm{D}$ pairs, and stemmed from both the determination of the top 15 pairs and the methods applied to collect the pertinent information once the top 15 pairs were selected. 
Two of the six TQOS measures, Passenger Loading QOS and Reliability QOS, were to be measured using field observations or data from APCs or AVL equipment (two systems in this evaluation used data from APCs and AVL; all others used manual observations for both loading and reliability). The $15 \mathrm{O}-\mathrm{D}$ pairs with the highest travel demands, as estimated by the local travel demand model, were to be selected for sampling of the passenger loading and reliability data. The objective was to measure how well transit serves the trips with the highest travel demands in the area.

There is no guidance in the reporting materials provided to the agencies concerning under what conditions, if any, one or more of the top 15 O-D pairs should be removed and substituted with other pairs. It might seem that, if both directions of an O-D pair appeared in the top 15 (e.g., CBD to Airport and Airport to CBD), one should be eliminated. However, this is not necessarily true. In most cases, the travel demand model estimated different levels of travel demand for each direction of an O-D pair. If the purpose of this TCQS effort is to measure the capacity and quality of service of transit in serving the origins and destinations with the highest demands, then none of the top 15 should be eliminated. However, one participant did remove O-D pairs in the top 15 if the pair traveling in the opposite direction was also included in the top 15 (although the travel demand figures were different). The O-D pairs with the next highest levels of travel demand were then substituted for these eliminated pairs, also ensuring that at least one trip including each of the 10 activity centers was surveyed. In addition, this participant also applied some reasoning as to which direction the trips were ultimately surveyed. For example, for a trip with high travel demand from a residential area to an employment center, the reverse trip was actually surveyed since the journey from the employment area to residential area would represent the p.m. peak travel pattern, despite the fact that the O-D pair in this direction was not one of the top 15 trips.

Two participants did not collect data on 15 trips; one used the 10 trips with the highest travel demands (they were instructed to do so in error) and another used 7 trips, 6 of which departed from the same origin and none of which were in the top $15 \mathrm{O}-\mathrm{D}$ pairs in terms of travel demands. Four other participants also substituted other O-D pairs for trips in the top 15. In one case, this was due to problems with APCs. Another participant collected information for eight of the top 15 trips and substituted seven others, and one other collected data for seven of the top 15 and substituted eight other trips, including the trip with the lowest travel demand of all 90 O-D pairs. At least one of these participants wished to evaluate at least one trip representing each of the activity centers and so "overrode" the top 15 trip selection based on the estimated travel demands. Finally, one participant only sampled four trips out of the top 15, substituting 11 others. In this case, the reason may be that this particular participant did not survey any 
trips that did not begin and end between 4:00 p.m. and 6:00 p.m., and so may have substituted other trips that could meet this criterion.

In another case, for a few O-D pairs, zero hours of service and zero travel opportunities per hour were noted, but other data on those trips were included (except loading and reliability). This may have been because this particular system did not take any measurements on trips that could not be completed between 4:00 p.m. and 6:00 p.m., although the Agency Reporting Guide states that measurements should be taken on trips departing the origin between 4:00 p.m. and 6:00 p.m. For four of another system's top 15 trips, zero travel opportunities per hour were reported, along with " $\mathrm{n} / \mathrm{a}$ " for transit travel time; yet other data were reported, including loading and reliability information. The reasons for these apparent discrepancies remain unclear.

For Passenger Loading QOS, eight participants collected fewer than the minimum sample size of 10 observations, with one system having only two or three observations for each of the top 15 trips. In some cases, fewer than 10 observations were made for all 15 trips, while in other cases, some of the 15 trips had fewer than 10 observations and the remaining trips had more than 10. Only four participants sampled fewer than 10 trip occurrences for the Reliability QOS measure. Some of the participants that had fewer than 10 observations for the Loading QOS had more than 10 observations for the Reliability QOS. This may stem from the fact that the section of the Agency Reporting Guide dealing with passenger loading did not explicitly state that a minimum of 10 observations was necessary for the Loading QOS, while it was specifically mentioned in the section regarding the Reliability QOS.

Service Coverage QOS could be calculated using either GIS or a manual method. Two participants in this evaluation calculated their service coverages manually. It would be difficult to use the individual participants' results for this measure in a statewide analysis of transit service coverage due to the fact that different types and different years of data were used. Data from the years 1990, 1995, 1996, 1997, 1998, 1999, and 2000 were utilized (three participants had year 2000 data available for use in this analysis). As 2000 data become more widely available in the coming year, all participants should be able to use the most recent data, thus facilitating a valid analysis of statewide transit service coverage.

The next section presents the statewide results of this first-year Transit Capacity and Quality of Service Evaluation. Results and references to individual participants in this evaluation are purposefully omitted since the objective is to examine quality of service on an aggregate statewide basis. 


\section{Review of the Statewide Results}

In an effort to provide a benchmark evaluation of transit systems within a similar time period, the overall performance of Florida transit systems was assessed using measures of current performance. Specifically, transit performance was evaluated using the six TQOS measures identified in this report. These measures included: service frequency, hours of service, service coverage, passenger loading, reliability, and transit versus auto travel time. As stated previously, these measures were evaluated to determine the level of service from the users' or riders' points of view and are represented by a scale of " $A$ " through " $F$," with " $A$ " representing the best service from the passenger's point of view, and " $F$ " representing the worst service.

All of the measures, with the exception of service coverage, were applied by all of the transit systems for a typical weekday afternoon peak period during March 2001. The following sections contain a description of each measure and the procedures used to accomplish the evaluation. In addition, the results of the evaluation are presented on a statewide level, as well as by transit system size. To preclude the comparison of systems of varying sizes, the analysis is presented by transit systems that operate fewer than 50 peak vehicles and transit systems that operate 50 peak vehicles or greater. In this evaluation, there are 10 transit systems with fewer than 50 peak vehicles and 7 transit systems with 50 peak vehicles or greater. It should be noted that the systems in Lakeland and Winter Haven were evaluated together as one system. The groups are presented in Tables 2 and 3.

Table 2: Transit Systems with Fewer than 50 Peak Vehicles - Small Systems

\begin{tabular}{|l|c|}
\hline \multicolumn{1}{|c|}{ System Name } & FY 2000 Peak Vehicles \\
\hline Ocala/Marion MPO (SunTran) & 5 \\
\hline Pasco County Public Transportation (PCPT) & 11 \\
\hline Manatee County Area Transit (MCAT) & 12 \\
\hline Space Coast Area Transit (SCAT - Brevard County) & 17 \\
\hline Sarasota County Area Transit (SCAT - Sarasota County) & 28 \\
\hline $\begin{array}{l}\text { Lakeland Area Mass Transit District/Winter Haven Area } \\
\text { Transit (Citrus Connection/WHAT) }\end{array}$ & 31 \\
\hline Escambia County Area Transit (ECAT) & 33 \\
\hline Lee County Transit (LeeTran) & 43 \\
\hline Tallahassee Transit (TalTran) & 44 \\
\hline County of Volusia dba VOTRAN & 46 \\
\hline
\end{tabular}


Table 3: Transit Systems with 50 Peak Vehicles or Greater - Large Systems

\begin{tabular}{|l|c|}
\hline \multicolumn{1}{|c|}{ System Name } & FY 2000 Peak Vehicles \\
\hline Regional Transit System (RTS-Gainesville) & 58 \\
\hline Palm Beach County Transportation Agency (PalmTran) & 125 \\
\hline Jacksonville Transportation Authority (JTA) & 157 \\
\hline Hillsborough Area Regional Transit Authority (HART) & 162 \\
\hline $\begin{array}{l}\text { Central Florida Regional Transit Authority } \\
\text { (Lynx - Orange, Seminole, and Osceola Counties) }\end{array}$ & 175 \\
\hline Broward County Mass Transit Division (BCT) & 230 \\
\hline Miami-Dade Transit (MDT) & 625 \\
\hline
\end{tabular}

\section{Service Frequency QOS}

An important measure in determining the quality of transit service from the perspective of the user is the frequency of scheduled service. The service frequency level of service is a measure of scheduled fixed-route and rail service and is usually measured either by headway or number of vehicles per hour. This measure is one of the most relied upon when determining customer satisfaction, and improving frequency is often considered when transit systems wish to strengthen their core ridership and attract new riders. While transit-dependent riders often have to adjust to the prevailing schedules, it is very difficult to attract discretionary riders out of their automobiles with infrequent service.

According to the TCQSM, the designated service frequency measure for urban scheduled service is headway. The relevant thresholds are shown in Table 4.

Table 4: Service Frequency QOS Thresholds

\begin{tabular}{|c|c|c|l|}
\hline QOS & $\begin{array}{c}\text { Headway } \\
\text { (min.) }\end{array}$ & $\begin{array}{c}\text { Vehicles } \\
\text { per Hour }\end{array}$ & \multicolumn{1}{|c|}{ Qualitative Threshold } \\
\hline A & $<10$ & $>6$ & Passengers do not need schedules \\
\hline B & $10-14$ & $5-6$ & Frequent service; passengers consult schedules \\
\hline C & $15-20$ & $3-4$ & Maximum desirable time to wait if bus/train missed \\
\hline D & $21-30$ & 2 & Service unattractive to choice riders \\
\hline E & $31-60$ & 1 & Service available once during hour \\
\hline F & $>60$ & $<1$ & Service unattractive to all riders \\
\hline
\end{tabular}

According to the standards, QOS A implies that transit vehicles arrive frequently enough that passengers need not refer to a route schedule to determine when the next vehicle will arrive. 
The other end of the spectrum presents transit service with headways greater than 60 minutes. QOS F represents a frequency that is unattractive to all riders, regardless of their level of dependency on transit service.

\section{Results - Statewide}

Table 5 illustrates the statewide frequency level of service results. As shown in the table, nearly half of the trip pairs involved in the evaluation (48.4 percent) received a Service Frequency QOS E, meaning that service was available only once during the hour for 681 origin-destination pairs or trips. Nearly 11 percent of the total trips evaluated perform at a frequency of QOS F.

Table 5: Service Frequency QOS -- Statewide

\begin{tabular}{|c|c|c|}
\hline QOS & $\begin{array}{c}\text { Number of } \\
\text { Total Trips }\end{array}$ & $\begin{array}{c}\text { Percent of } \\
\text { Total Trips }\end{array}$ \\
\hline A & 15 & $1.1 \%$ \\
\hline B & 17 & $1.2 \%$ \\
\hline C & 179 & $12.7 \%$ \\
\hline D & 362 & $25.7 \%$ \\
\hline E & 681 & $48.4 \%$ \\
\hline F & 152 & $10.8 \%$ \\
\hline Total & 1,406 & $100.0 \%$ \\
\hline
\end{tabular}

Results - Transit Systems with Fewer than 50 Peak Vehicles

The Service Frequency QOS for the systems with fewer than 50 peak vehicles is presented in Table 6. Over half of the evaluated trips for the smaller systems (fewer than 50 peak vehicles) are available to passengers only once during the hour. Just as with the statewide frequency evaluations, QOS E represents more of the smaller systems trips than any other Service Frequency QOS. None of the evaluated trips for the smaller systems earned a frequency QOS A. This is not surprising, as many smaller systems do not have the resources to provide the type of service that allows passengers to ride without consulting a schedule. 
Table 6: Service Frequency QOS Results - Small Systems

\begin{tabular}{|c|c|c|c|}
\hline QOS & Number of Trips & Percent of Trips & Portion of Total Statewide Trips \\
\hline A & 0 & $0.0 \%$ & $0.0 \%$ \\
\hline B & 3 & $0.4 \%$ & $17.6 \%$ \\
\hline C & 48 & $5.8 \%$ & $26.8 \%$ \\
\hline D & 201 & $24.4 \%$ & $55.5 \%$ \\
\hline E & 490 & $59.5 \%$ & $72.0 \%$ \\
\hline F & 82 & $10.0 \%$ & $53.9 \%$ \\
\hline Total & 824 & $100.0 \%$ & \\
\hline
\end{tabular}

Results - Transit Systems with 50 Peak Vehicles or Greater

The frequency QOS distribution for this group of transit agencies is presented in Table 7. As shown in the table, most of the evaluated trips by the larger systems performed at a frequency QOS E, which mirrors the statewide distribution. However, the trips by the larger systems only account for 28 percent of the 681 statewide trips earning a QOS E. This is somewhat expected, as larger systems tend to have more resources with which to increase frequency. The larger systems accounted for 100 percent of the trips on which service is so frequent that passengers would not need to consult a schedule (QOS A). However, this only accounted for 2.6 percent of the total trips by the larger systems. Instead, most of the trips evaluated earned a QOS D or worse (72.5 percent), implying that many larger transit systems are providing service at frequencies that are unattractive to most riders.

Table 7: Service Frequency QOS Results - Large Systems

\begin{tabular}{|c|c|c|c|}
\hline QOS & Number of Trips & Percent of Trips & Portion of Total Statewide Trips \\
\hline A & 15 & $2.6 \%$ & $100.0 \%$ \\
\hline B & 14 & $2.4 \%$ & $82.3 \%$ \\
\hline C & 131 & $22.5 \%$ & $73.2 \%$ \\
\hline D & 161 & $27.7 \%$ & $44.4 \%$ \\
\hline E & 191 & $32.8 \%$ & $28.0 \%$ \\
\hline F & 70 & $12.0 \%$ & $46.1 \%$ \\
\hline Total & 582 & $100.0 \%$ & \\
\hline
\end{tabular}




\section{Hours of Service QOS}

Another important criteria for determining transit service convenience and frequency from the perspective of the passenger is the hours of operation. Survey efforts, such as those conducted in Transit 2020, suggest that a major complaint of existing users regarding transit service is limited hours of operation. For those passengers who must depend on transit service, inconvenient hours of operation generally require that they adjust their activities and schedules to utilize the service. For those users who have alternative means of travel, they may simply opt to not use transit when the hours of service are limited.

In the TCQS evaluation, the Hours of Service QOS is a measure of the number of scheduled hours of operation for fixed-route and rail service in a 24-hour period. The number of hours that a transit system operates daily is usually indicative of the type of service and has a significant impact on the kind of users that are attracted to the service. Specifically, the evaluation required that each participating agency or MPO determine the earliest and latest departure time in the day at which several origin-destination trips could be made. The hours between these times were used to determine transit hours of service. Table 8 illustrates the designated Hours of Service QOS from the TCQSM.

Table 8: Hours of Service QOS Thresholds

\begin{tabular}{|c|c|l|}
\hline QOS & Hours Per Day & \multicolumn{1}{|c|}{ Type of Service Provided } \\
\hline A & $19-24$ & Night or owl service \\
\hline B & $17-18$ & Late evening service \\
\hline C & $14-16$ & Early evening service \\
\hline D & $12-13$ & Daytime service \\
\hline E & $4-11$ & Peak hour service/limited midday \\
\hline F & $0-3$ & Very limited or no service \\
\hline
\end{tabular}

These standards were established under the assumption that passengers find transit systems that operate well beyond the typical work day hours more attractive. Those systems that provide early morning and late night service are considered most convenient from the point of view of the passenger and, consequently, earn a QOS A. On the other hand, the lowest-rated level of service is reserved for those systems that provide very limited service to no service at all. 


\section{Results - Statewide}

Table 9 shows the statewide distribution of Hours of Service QOS results. As the table indicates, most of the trips involved in the evaluation (28.9 percent) represent systems in which daytime service is typical (QOS D). Nearly 40 percent of the total trips evaluated represent systems that provide some type of evening or night service on at least some routes (QOS A, B, or C).

Table 9: Hours of Service QOS Results -- Statewide

\begin{tabular}{|c|c|c|}
\hline QOS & Number of Total Trips & Percent of Total Trips \\
\hline A & 88 & $6.3 \%$ \\
\hline B & 159 & $11.3 \%$ \\
\hline C & 297 & $21.1 \%$ \\
\hline D & 407 & $28.9 \%$ \\
\hline E & 278 & $19.8 \%$ \\
\hline F & 177 & $12.6 \%$ \\
\hline Total & 1,406 & $100.0 \%$ \\
\hline
\end{tabular}

Results - Transit Systems with Fewer than 50 Peak Vehicles

The Hours of Service QOS for this group of transit agencies is presented in Table 10. The table illustrates that most of the evaluated trips by smaller systems are made on routes that operate at 13 hours per day or less. Similar to Frequency QOS, the ability of smaller agencies to operate at hours well beyond the typical workday may be severely limited by the resources available, as such expansion in hours is a labor-intensive investment. Although the table does not reveal it, all of the six trips that earned a QOS A (night or owl service provided) for smaller systems were provided by one system. This particular system provides, with the exception of the six trips provided at late night or owl hours, peak service only. While the late night hours are an anomaly among smaller systems, the significant provision of peak hour service only on particular routes is common. Table 10 shows that 29.6 percent of small system trips are available during peak hour/limited midday service only and 17.1 percent of small system trips are available three hours of the day or less. 
Table 10: Hours of Service QOS Results - Small Systems

\begin{tabular}{|c|c|c|c|}
\hline QOS & Number of Trips & Percent of Trips & Portion of Total Statewide Trips \\
\hline A & 6 & $0.7 \%$ & $6.8 \%$ \\
\hline B & 2 & $0.2 \%$ & $1.3 \%$ \\
\hline C & 142 & $17.2 \%$ & $47.8 \%$ \\
\hline D & 289 & $35.1 \%$ & $71.0 \%$ \\
\hline E & 244 & $29.6 \%$ & $87.8 \%$ \\
\hline F & 141 & $17.1 \%$ & $79.7 \%$ \\
\hline Total & 824 & $100.0 \%$ & \\
\hline
\end{tabular}

Results - Transit Systems with 50 Peak Vehicles or Greater

The evaluated trips representing the larger systems fared much better with regard to the number of hours during which transit service is provided. As Table 11 demonstrates, the number of trips was distributed fairly evenly among QOS B, C, and D (12-18 hours per day), with a slight edge in the number of trips available 14-16 hours per day. Very few of the large system trips that were evaluated (12 percent) had very limited or peak hour service only.

Table 11: Hours of Service QOS Results - Large Systems

\begin{tabular}{|c|c|c|c|}
\hline QOS & Number of Trips & Percent of Trips & Portion of Total Statewide Trips \\
\hline A & 82 & $14.1 \%$ & $93.2 \%$ \\
\hline B & 157 & $27.0 \%$ & $98.7 \%$ \\
\hline C & 155 & $26.6 \%$ & $52.2 \%$ \\
\hline D & 118 & $20.3 \%$ & $29.0 \%$ \\
\hline E & 34 & $5.8 \%$ & $12.2 \%$ \\
\hline F & 36 & $6.2 \%$ & $20.3 \%$ \\
\hline Total & 582 & $100.0 \%$ & \\
\hline
\end{tabular}

\section{Service Coverage QOS}

Another good indicator of passengers' satisfaction with transit service is whether the bus provides service to the areas where they want to go. Generally, those areas of high population and employment densities are good candidates for transit service. The quality of service measure for service coverage is the percent of the transit-supportive area served for each particular system. For this evaluation, an area is considered transit-supportive if it has a 
minimum population and/or employment density to support at least hourly service. A density of three houses per acre or four employees per acre is required, and the area must be within walking distance (within one-quarter mile of a bus stop or one-half mile of a rail or busway station) to transit service. Units of measurement could include any defined geographic area such as a quarter section, census tract or block group, or TAZ. Table 12 illustrates the Service Coverage QOS thresholds found in the TCQSM used to evaluate the transit systems.

Table 12: Service Coverage QOS Thresholds

\begin{tabular}{|c|c|}
\hline QOS & \% Transit-Supportive Area Covered \\
\hline A & $90.0-100.0$ \\
\hline B & $80.0-89.9$ \\
\hline C & $70.0-79.9$ \\
\hline D & $60.0-69.9$ \\
\hline E & $50.0-59.9$ \\
\hline F & $<50.0$ \\
\hline
\end{tabular}

Results - Statewide

Table 13 shows the distribution of all of the systems in the state along the Service Coverage QOS spectrum. Five of the 17 participating agencies (29.4 percent) represent QOS F, i.e., have service coverage of less than 50 percent of the transit-supportive area. While this suggests that several transit agencies are not providing access to areas having sufficient population or employment activity to warrant some type of transit service, Table 13 also indicates that nearly 65 percent of the agencies have service coverage in at least 60 percent of their transit-supportive areas (at least QOS D). Interestingly, no system, small or large, has a Service Coverage QOS B. It is important to note the difficulty in interpreting the statewide service coverage information. Participating areas used different methodologies (GIS versus manual calculations) and varying years of data (from 1990 to 2000 and nearly every year in between) to determine Service Coverage QOS. With the continuing release of Census 2000 data, the analysis of this measure should be more meaningful with the next effort. 
Table 13: Service Coverage QOS Results -- Statewide

\begin{tabular}{|c|c|c|}
\hline QOS & Number of Systems & Percent of All Systems \\
\hline A & 4 & $23.5 \%$ \\
\hline B & 0 & $0.0 \%$ \\
\hline C & 4 & $23.5 \%$ \\
\hline D & 3 & $17.6 \%$ \\
\hline E & 1 & $5.9 \%$ \\
\hline F & 5 & $29.4 \%$ \\
\hline Total & 17 & $100.0 \%$ \\
\hline
\end{tabular}

Results - Transit Systems with Fewer than 50 Peak Vehicles

The smaller systems seemed to fare better than the larger systems for the Service Coverage QOS measure. This could be partly due to the fact that smaller systems may have fewer transitsupportive areas to be covered. As Table 14 shows, the systems are distributed fairly evenly among the QOS categories, with the exception of QOS B.

Table 14: Service Coverage QOS Results - Small Systems

\begin{tabular}{|c|c|c|c|}
\hline QOS & Number of Systems & Percent of Small Systems & Percent of All Systems \\
\hline A & 2 & $20.0 \%$ & $50.0 \%$ \\
\hline B & 0 & $0.0 \%$ & $0.0 \%$ \\
\hline C & 3 & $30.0 \%$ & $75.0 \%$ \\
\hline D & 1 & $10.0 \%$ & $33.3 \%$ \\
\hline E & 1 & $10.0 \%$ & $100.0 \%$ \\
\hline F & 3 & $30.0 \%$ & $60.0 \%$ \\
\hline Total & 10 & $100.0 \%$ & \\
\hline
\end{tabular}

Results - Transit Systems with 50 Peak Vehicles or Greater

Table 15 illustrates that service coverage of the larger systems is relatively consistent among the QOS A through F rating. In fact, QOS A (coverage to 90.0 to 100.0 percent of the transitsupportive area), QOS D (coverage to 60.0 to 69.9 percent of the transit-supportive area), and QOS F (coverage to only 50.0 to 59.9 percent of the transit-supportive area) each accounted for two of seven $(28.6 \%)$ of the large systems' results. 
Table 15: Service Coverage LOS Results - Large Systems

\begin{tabular}{|c|c|c|c|}
\hline LOS & Number of Systems & Percent of Large Systems & Percent of All Systems \\
\hline A & 2 & $28.6 \%$ & $50.0 \%$ \\
\hline B & 0 & $0.0 \%$ & $0.0 \%$ \\
\hline C & 1 & $14.3 \%$ & $25.0 \%$ \\
\hline D & 2 & $28.6 \%$ & $66.7 \%$ \\
\hline E & 0 & $0.0 \%$ & $0.0 \%$ \\
\hline F & 2 & $28.6 \%$ & $40.0 \%$ \\
\hline Total & 7 & 100.0 & \\
\hline
\end{tabular}

\section{Passenger Loading QOS}

While a crowded bus signals tremendous ridership, in the case of this evaluation a crowded bus represents an undesirable situation for the transit passenger. Passenger loading denotes the degree of crowding on a transit vehicle and is defined by the load factor, which is the amount of space available per passenger on the vehicle. Table 16 identifies the passenger loading measure thresholds for both bus and rail as identified in the TCQSM. Note, however, that none of Florida's systems use the rail threshold, except for Miami-Dade Transit.

Table 16: Passenger Loading QOS Thresholds

\begin{tabular}{|c|c|c|c|c|l|}
\hline \multirow{2}{*}{ QOS } & \multicolumn{2}{|c|}{ Bus } & \multicolumn{2}{c|}{ Rail } & \multirow{2}{*}{ Qualitative Threshold } \\
\cline { 2 - 5 } & Sq Ft./Pass. & Pass./Seat & Sq Ft./Pass & Pass./Seat & \\
\hline A & $>12.9$ & $0.00-0.50$ & $>19.9$ & $0.00-0.50$ & No passenger needs to sit next to another \\
\hline B & $8.6-12.9$ & $0.51-0.75$ & $14.0-19.9$ & $0.51-0.75$ & Passengers can choose where to sit \\
\hline C & $6.5-8.5$ & $0.76-1.00$ & $10.2-13.9$ & $0.76-1.00$ & All passengers can sit \\
\hline D & $5.4-6.4$ & $1.01-1.25$ & $5.4-10.1$ & $1.01-2.00$ & Comfortable standee load for design \\
\hline E & $4.3-5.3$ & $1.25-1.50$ & $3.2-5.3$ & $2.01-3.00$ & Maximum schedule load \\
\hline F & $<4.3$ & $>1.50$ & $<3.2$ & $>3.00$ & Crush loads \\
\hline
\end{tabular}

For many of the agencies conducting this evaluation, it was inconceivable that empty transit vehicles warranted the better QOS. However, loading from the perspectives of the transit rider and transit provider represent two very different views. Since this evaluation represents the perspective of the passenger, QOS A indicates that there are so many seats available on the transit vehicle that passengers can choose where to sit and do not need to sit next to any other passenger(s). This condition exists until the vehicle is half full. At the other end of the 
spectrum, QOS F represents those situations where all seats are occupied and there are at least half that many more passengers standing in the transit vehicle.

Each transit agency was only required to calculate the Passenger Loading QOS for the 15 O-D pairs with the highest travel demands. Measurements were to be taken at the maximum load point. If the transit trip from the origin to the destination required a transfer, measurements were taken at the maximum load point of the first segment only. Two of the agencies were able to utilize APC units; however, most of the participants collected this information manually.

Results - Statewide

According to Table 17, most of the trips on which passenger loading was measured were on transit vehicles that had sufficient seat availability such that passengers could be selective when choosing their seats. As shown in the table, QOS A far exceeded the other levels of service with 83.9 percent of the trips of highest demand. Very few of the agencies' top trips were crowded such that QOS F was earned. In fact, the seven trips with QOS F came from one transit agency.

Table 17: Passenger Loading QOS Results -- Statewide

\begin{tabular}{|c|c|c|c|}
\hline QOS & Determinant (Pass./Seat) & Number of Top Trips* & Percent of Top Trips* $^{*}$ \\
\hline A & $0.00-0.50$ & 177 & $83.9 \%$ \\
\hline B & $0.51-0.75$ & 19 & $9.0 \%$ \\
\hline C & $0.76-1.00$ & 3 & $1.4 \%$ \\
\hline D & $1.01-1.25 / 1.01-2.00^{* *}$ & 0 & $0.0 \%$ \\
\hline E & $1.25-1.50 / 2.01-3.00^{* *}$ & 5 & $2.4 \%$ \\
\hline F & $>1.50 />3.00^{* *}$ & 7 & $3.3 \%$ \\
\hline Total & & 211 & $100.0 \%$ \\
\hline
\end{tabular}

* Loading data were collected on the top 15 trips in most cases. Some agencies collected these data for fewer than the 15 trips with the highest travel demands, and other trips were substituted. This analysis focuses on the 15 trips with the highest travel demands only. The total number of trips analyzed for this purpose is 211.

${ }^{* *}$ Denotes measurements for a rail vehicle, as opposed to a bus.

\section{Results - Transit Systems with Fewer than 50 Peak Vehicles}

Nearly all of the evaluated trips (122 of 129, or 94.6 percent) for small systems had 0.50 passengers per seat or less (QOS A). The remaining trips (seven, or 5.5 percent), which earned QOS B (five) and QOS E (two), were from two transit agencies. While this is not surprising, it indicates that none of the small systems is having problems specific to overcrowding on buses. Table 18 shows the distribution of the Passenger Loading QOS results for transit systems with fewer than 50 peak vehicles. 
Table 18: Passenger Loading QOS Results - Small Systems

\begin{tabular}{|c|c|c|c|}
\hline QOS & Determinant (Pass./Seat) & Number of Top Trips & Percent of Top Trips \\
\hline A & $0.00-0.50$ & 122 & $94.6 \%$ \\
\hline B & $0.51-0.75$ & 5 & $3.9 \%$ \\
\hline C & $0.76-1.00$ & 0 & $0.0 \%$ \\
\hline D & $1.01-1.25$ & 0 & $0.0 \%$ \\
\hline E & $1.25-1.50$ & 2 & $1.6 \%$ \\
\hline F & $>1.50$ & 0 & $0.0 \%$ \\
\hline Total & & 129 & $100.0 \%$ \\
\hline
\end{tabular}

\section{Results - Transit Systems with 50 Peak Vehicles or Greater}

The distribution of Passenger Loading QOS results for the larger systems, as Table 19 indicates, is more dispersed among the various levels. While the majority of the top trips for the larger systems were on vehicles with loads that allowed passengers to choose where they would like to sit (84.2 percent, QOS A and B), there also were trips which earned QOS C, E, and F.

Table 19: Passenger Loading QOS Results - Large Systems

\begin{tabular}{|c|c|c|c|}
\hline QOS & Determinant (Pass./Seat) & Number of Top Trips & Percent of Top Trips \\
\hline A & $0.00-0.50$ & 55 & $67.1 \%$ \\
\hline B & $0.51-0.75$ & 14 & $17.1 \%$ \\
\hline C & $0.76-1.00$ & 3 & $3.7 \%$ \\
\hline D & $1.01-1.25 / 1.01-2.00^{*}$ & 0 & $0.0 \%$ \\
\hline E & $1.25-1.50 / 2.01-3.00^{*}$ & 3 & $3.7 \%$ \\
\hline F & $>1.50 />3.00^{*}$ & 7 & $8.5 \%$ \\
\hline Total & & 82 & $100.0 \%$ \\
\hline
\end{tabular}

${ }^{*}$ Denotes measurements for a rail vehicle, as opposed to a bus.

\section{Reliability QOS}

The reliability quality of service measure reflects a comparison of actual versus scheduled arrival times of transit vehicles at stops or stations that reflect the maximum load point of the first segment required to take the trip via transit (assuming a transfer is involved; if not, the maximum load point of the route was used for the appropriate direction of travel). On-time performance is a critical factor when evaluating a transit system, as it is indicative of the degree 
to which passengers can depend on the service. On-time performance is defined as the arrival of the transit vehicle within five minutes of the printed time on the schedule. Trips that are either earlier or more than five minutes later than the time on the schedule are identified as not being on time. Table 20 identifies the Reliability QOS thresholds as defined in the TCQSM.

Table 20: Reliability QOS Thresholds

\begin{tabular}{|c|c|l|}
\hline QOS & On-Time Percentage & \multicolumn{1}{c|}{ Result } \\
\hline A & $97.5-100.0 \%$ & 1 late transit vehicle per month \\
\hline B & $95.0-97.4 \%$ & 2 late transit vehicles per month \\
\hline C & $90.0-94.4 \%$ & 1 late transit vehicle per week \\
\hline D & $85.0-89.9 \%$ & More than one late transit vehicle per week \\
\hline E & $80.0-84.9 \%$ & 1 late transit vehicle per direction per week \\
\hline F & $<80.0 \%$ & More than two late transit vehicles per week \\
\hline
\end{tabular}

An agency receiving a QOS A has been able to maintain its schedule at least 97.5 percent of the time. Understandably, this is the most desirable situation for a passenger who uses the transit service. At the other end of the spectrum, an agency that maintains an on-time rate of less than 80 percent will have a difficult time attracting discretionary transit riders and will risk greatly inconveniencing its core riders. For example, with Reliability QOS E or F, a passenger making a work trip will be late at least one day per week.

\section{Results - Statewide}

The distribution of statewide Reliability QOS results reveals that, while the majority of the top trips made reflect poor reliability (55.5 percent received QOS F), there are several trips for which the agencies have been able to maintain a high level of on-time performance (20.4 percent received QOS A). Table 21 outlines these results. 
Table 21: Reliability QOS Results - Statewide

\begin{tabular}{|c|c|c|}
\hline QOS & Number of Top Trips & Percent of Top Trips \\
\hline A & 43 & $20.4 \%$ \\
\hline B & 1 & $0.5 \%$ \\
\hline C & 22 & $10.4 \%$ \\
\hline D & 3 & $1.4 \%$ \\
\hline E & 25 & $11.8 \%$ \\
\hline F & 117 & $55.5 \%$ \\
\hline Total & 211 & $100.0 \%$ \\
\hline
\end{tabular}

\section{Results - Transit Systems with Fewer than 50 Peak Vehicles}

Table 22 indicates that the distribution of Reliability QOS results for the smaller systems mirrors the statewide results in that a clear majority of the trips evaluated exhibited on-time performance levels of less than 80 percent. The small systems appear to have been better able to maintain their on-time performance, however, which is partly evident by the fact that 32 of the 43 statewide trips earning QOS A are from small systems.

Table 22: Reliability QOS Results - Small Systems

\begin{tabular}{|c|c|c|}
\hline QOS & Number of Top Trips & Percent of Top Trips \\
\hline A & 32 & $24.8 \%$ \\
\hline B & 0 & $0.0 \%$ \\
\hline C & 14 & $10.9 \%$ \\
\hline D & 0 & $0.0 \%$ \\
\hline E & 17 & $13.2 \%$ \\
\hline F & 66 & $51.2 \%$ \\
\hline Total & 129 & $100.0 \%$ \\
\hline
\end{tabular}

Results - Transit Systems with 50 Peak Vehicles or Greater

The larger systems did not appear to fare as well in the reliability evaluation. Presumably, larger systems operate in larger, more dense geographic areas where traffic congestion could possibly play more of a significant role in on-time performance. These results are shown in Table 23. 
Table 23: Reliability QOS Results - Large Systems

\begin{tabular}{|c|c|c|}
\hline QOS & Number of Top Trips & Percent of Top Trips \\
\hline A & 11 & $13.4 \%$ \\
\hline B & 1 & $1.2 \%$ \\
\hline C & 8 & $9.8 \%$ \\
\hline D & 3 & $3.7 \%$ \\
\hline E & 8 & $9.8 \%$ \\
\hline F & 51 & $62.2 \%$ \\
\hline Total & 97 & $100.0 \%$ \\
\hline
\end{tabular}

\section{Transit versus Auto Travel Time}

The remaining service measure compares the travel time between selected origins and destinations using both transit schedules and model-derived estimates for automobile travel. For those passengers who have alternatives for transit, particularly an automobile, travel time is almost always a factor in deciding which to use. For this evaluation, transit versus auto travel time is determined by measuring the total difference in travel time from an origin to a destination between transit and auto. Issues regarding the disparity in the methods of determining these travel times have been discussed in this report. Many of the participants in this first-time evaluation expressed concern over the model estimates being used to calculate auto travel time, with some indicating that the only valid technique would be to determine auto travel times by actually test-driving an auto on the trip on the same day(s) that transit measurements are taken. Table 24 identifies thresholds for this measure as presented in the TCQSM.

Table 24: Transit versus Auto Travel Time QOS Thresholds

\begin{tabular}{|c|c|l|}
\hline QOS & Travel Time Difference (minutes) & \multicolumn{1}{c|}{ Threshold } \\
\hline A & $<=0$ & As fast or faster by transit than by auto \\
\hline B & $1-15$ & About as fast by transit as by auto \\
\hline C & $16-30$ & Tolerable choice for riders \\
\hline D & $31-45$ & Round-trip at least an hour longer by transit \\
\hline E & $46-60$ & Tedious for all riders; may be best possible in small cities \\
\hline F & $>60$ & Unacceptable to most riders \\
\hline
\end{tabular}




\section{Results - Statewide}

According the results identified in Table 25, nearly 30 percent of the trips evaluated for travel time would be considered unacceptable to most riders. While nearly five percent of trips evaluated were determined to be as fast or faster by transit than by auto (QOS A), the remaining trips appear to be distributed fairly evenly among the QOS scores of B, C, D, and E.

Table 25: Transit vs. Auto Travel Time QOS -- Statewide

\begin{tabular}{|c|c|c|}
\hline LOS & Number of Total Trips & Percent of Total Trips \\
\hline A & 69 & $4.9 \%$ \\
\hline B & 281 & $20.0 \%$ \\
\hline C & 240 & $17.1 \%$ \\
\hline D & 203 & $14.4 \%$ \\
\hline E & 193 & $13.7 \%$ \\
\hline F & 420 & $29.9 \%$ \\
\hline Total & 1406 & $100.0 \%$ \\
\hline
\end{tabular}

Results - Transit Systems with Fewer than 50 Peak Vehicles

According to the results included in Table 26, patrons of smaller systems are more likely to be able to take one of the evaluated trips just as fast on transit as by auto (QOS A or B). However, over 35 percent of the trips are estimated to take more than 45 minutes longer by transit than by auto (QOS E or F).

Table 26: Transit vs. Auto Travel Time QOS - Small Systems

\begin{tabular}{|c|c|c|}
\hline QOS & Number of Total Trips & Percent of Total Trips \\
\hline A & 59 & $7.2 \%$ \\
\hline B & 211 & $25.6 \%$ \\
\hline C & 156 & $18.9 \%$ \\
\hline D & 107 & $13.0 \%$ \\
\hline E & 102 & $12.4 \%$ \\
\hline F & 189 & $22.9 \%$ \\
\hline Total & 824 & $100.0 \%$ \\
\hline
\end{tabular}


Clearly, the majority of the evaluated trips taken on larger systems had travel times that would be considered unacceptable by most passengers. Just as reliability is affected by traffic congestion, travel time is affected in the same manner. Consequently, it is not surprising that many of the larger transit systems experience difficulty in maintaining faster travel times. Nearly 14 percent of the trips are about as fast by transit as by auto or faster (QOS A or B), according to Table 27. In contrast, more than 55 percent of the trips are estimated to take at least 45 minutes longer by transit than by auto (QOS E or F).

Table 27: Transit vs. Auto Travel Time QOS - Large Systems

\begin{tabular}{|c|c|c|}
\hline QOS & Number of Total Trips & Percent of Total Trips \\
\hline A & 10 & $1.7 \%$ \\
\hline B & 70 & $12.0 \%$ \\
\hline C & 84 & $14.4 \%$ \\
\hline D & 96 & $16.5 \%$ \\
\hline E & 91 & $15.6 \%$ \\
\hline F & 231 & $39.7 \%$ \\
\hline Total & 582 & $100.0 \%$ \\
\hline
\end{tabular}

\section{Summary}

The information that has been presented comprises a statewide evaluation of Florida's transit systems in terms of the TCQS framework. Table 28 below summarizes the Service Coverage QOS information for the state as a whole, larger systems, and smaller systems. Tables 29 through 31 similarly summarize the remaining QOS measures, which deal with trips between specific O-D pairs representing major activity centers within individual agencies' areas.

Table 28: Service Coverage QOS Results -- Summary

\begin{tabular}{|c|c|c|c|}
\hline QOS & Statewide & Small Systems $(<\mathbf{5 0}$ Peak Vehs) & Large Systems (> 50 Vehs) \\
\hline A & 4 systems $(23.5 \%)$ & 2 systems $(20.0 \%)$ & 2 systems $(28.6 \%)$ \\
\hline B & 0 systems $(0.0 \%)$ & 0 systems $(0.0 \%)$ & 0 systems $(0.0 \%)$ \\
\hline C & 4 systems $(23.5 \%)$ & 3 systems $(30.0 \%)$ & 1 system $(14.3 \%)$ \\
\hline D & 3 systems $(17.6 \%)$ & 1 system $(10.0 \%)$ & 2 systems $(28.6 \%)$ \\
\hline E & 1 system $(5.9 \%)$ & 1 system $(10.0 \%)$ & 0 systems $(0.0 \%)$ \\
\hline F & 5 systems $(29.4 \%)$ & 3 systems $(20.0 \%)$ & 2 systems $(28.6 \%)$ \\
\hline Total & 17 systems $(100.0 \%)$ & 10 systems $(100.0 \%)$ & 7 systems $(100.0 \%)$ \\
\hline
\end{tabular}


Table 29: TCQS Results - Summary of All O-D Pairs Service Frequency, Hours of Service, and Travel Time QOS

\begin{tabular}{|c|c|c|c|c|c|c|c|c|c|}
\hline \multirow{2}{*}{ QOS } & \multicolumn{2}{|c|}{ Service Frequency QOS } & \multicolumn{2}{c|}{ Hours of Service QOS } & \multicolumn{3}{|c|}{ Travel Time QOS } \\
\cline { 2 - 10 } & State & Small & Large & State & Small & Large & State & Small & Large \\
\hline A & $1.1 \%$ & $0.0 \%$ & $2.6 \%$ & $6.3 \%$ & $0.7 \%$ & $14.1 \%$ & $4.9 \%$ & $7.2 \%$ & $1.7 \%$ \\
\hline B & $1.2 \%$ & $0.4 \%$ & $2.4 \%$ & $11.3 \%$ & $0.2 \%$ & $27.0 \%$ & $20.0 \%$ & $25.6 \%$ & $12.0 \%$ \\
\hline C & $12.7 \%$ & $5.8 \%$ & $22.5 \%$ & $21.1 \%$ & $17.2 \%$ & $26.6 \%$ & $17.1 \%$ & $18.9 \%$ & $14.4 \%$ \\
\hline D & $25.7 \%$ & $24.4 \%$ & $27.7 \%$ & $28.9 \%$ & $35.1 \%$ & $20.3 \%$ & $14.4 \%$ & $13.0 \%$ & $16.5 \%$ \\
\hline E & $48.4 \%$ & $59.5 \%$ & $32.8 \%$ & $19.8 \%$ & $29.6 \%$ & $5.8 \%$ & $13.7 \%$ & $12.4 \%$ & $15.6 \%$ \\
\hline F & $10.8 \%$ & $10.0 \%$ & $12.0 \%$ & $12.6 \%$ & $17.1 \%$ & $6.2 \%$ & $29.9 \%$ & $22.9 \%$ & $39.7 \%$ \\
\hline
\end{tabular}

NOTE: "State" denotes total pairs; "Small" is < 50 peak vehicle systems; "Large" is > 50 peak vehicle systems.

Table 30: TCQS Results - Summary of Top 15 O-D Pairs Service Frequency, Hours of Service, and Travel Time QOS

\begin{tabular}{|c|c|c|c|c|c|c|c|c|c|}
\hline \multirow{2}{*}{ QOS } & \multicolumn{2}{|c|}{ Service Frequency QOS } & \multicolumn{2}{c|}{ Hours of Service QOS } & \multicolumn{3}{|c|}{ Travel Time QOS } \\
\cline { 2 - 10 } & State & Small & Large & State & Small & Large & State & Small & Large \\
\hline A & $0.8 \%$ & $0.0 \%$ & $1.9 \%$ & $7.9 \%$ & $0.7 \%$ & $17.1 \%$ & $9.1 \%$ & $11.7 \%$ & $5.7 \%$ \\
\hline B & $2.1 \%$ & $0.7 \%$ & $3.8 \%$ & $12.4 \%$ & $1.5 \%$ & $26.7 \%$ & $31.8 \%$ & $41.6 \%$ & $19.0 \%$ \\
\hline C & $21.5 \%$ & $16.8 \%$ & $27.6 \%$ & $26.0 \%$ & $27.0 \%$ & $24.8 \%$ & $18.2 \%$ & $14.6 \%$ & $22.9 \%$ \\
\hline D & $28.5 \%$ & $32.1 \%$ & $23.8 \%$ & $29.8 \%$ & $38.7 \%$ & $18.1 \%$ & $14.5 \%$ & $11.7 \%$ & $18.1 \%$ \\
\hline E & $40.9 \%$ & $47.4 \%$ & $32.4 \%$ & $20.2 \%$ & $29.9 \%$ & $7.6 \%$ & $8.7 \%$ & $9.5 \%$ & $7.6 \%$ \\
\hline F & $6.2 \%$ & $2.9 \%$ & $10.5 \%$ & $3.7 \%$ & $2.2 \%$ & $5.7 \%$ & $17.8 \%$ & $10.9 \%$ & $26.7 \%$ \\
\hline
\end{tabular}

NOTE: "State" denotes total pairs; "Small" is < 50 peak vehicle systems; "Large" is > 50 peak vehicle systems.

Table 31: TCQS Results - Summary of Top 15 O-D Pairs Passenger Loading and Reliability QOS

\begin{tabular}{|c|c|c|c|c|c|c|}
\hline \multirow{2}{*}{ QOS } & \multicolumn{2}{|c|}{ Passenger Loading QOS } & \multicolumn{3}{c|}{ Reliability QOS } \\
\cline { 2 - 7 } & State & Small & Large & State & Small & Large \\
\hline A & $83.9 \%$ & $94.6 \%$ & $67.1 \%$ & $20.4 \%$ & $24.8 \%$ & $13.4 \%$ \\
\hline B & $9.0 \%$ & $3.9 \%$ & $17.1 \%$ & $0.5 \%$ & $0.0 \%$ & $1.2 \%$ \\
\hline C & $1.4 \%$ & $0.0 \%$ & $3.7 \%$ & $10.4 \%$ & $10.9 \%$ & $9.8 \%$ \\
\hline D & $0.0 \%$ & $0.0 \%$ & $0.0 \%$ & $1.4 \%$ & $0.0 \%$ & $3.7 \%$ \\
\hline E & $2.4 \%$ & $1.6 \%$ & $3.7 \%$ & $11.8 \%$ & $13.2 \%$ & $9.8 \%$ \\
\hline F & $3.3 \%$ & $0.0 \%$ & $8.5 \%$ & $55.5 \%$ & $51.2 \%$ & $62.2 \%$ \\
\hline
\end{tabular}

NOTE: "State" denotes total pairs; "Small" is < 50 peak vehicle systems; "Large" is $>50$ peak vehicle systems. 


\section{CONCLUSIONS AND RECOMMENDATIONS}

The first-year Transit Capacity and Quality of Service Evaluation proved to be a valuable learning experience for everyone involved: participating MPOs and transit systems, FDOT, and consultants and researchers who assisted in this effort. Undoubtedly, the developers of this evaluation process also can learn from this first statewide application of their work. While a detailed presentation of the statewide TQOS results is included in this report, significant emphasis also is placed on the process of the evaluation itself, since it is understood that this year's results are not as robust as those that would be obtained in future efforts when those involved gain a greater understanding of the process and methodologies. Exhaustive interviews were conducted with representatives of each participating agency (MPOs, transit systems, and consultants) to obtain insight as to how the process unfolded in each individual area and to identify obstacles, problems, and issues that arose during the conduct of the evaluation. In addition, while only statewide results are presented in this report, the results from individual areas have been analyzed separately not only to see if the outcomes matched expectations but to ascertain how the process was applied in each area. It is important that each participating area follow the same established procedures and apply the TQOS measures consistently to ensure a valid statewide representation of transit capacity and quality of service. This section summarizes the major issues that surfaced during the course of the evaluation and presents a series of recommendations that will help ensure the most valid results from this process in the future.

1- The minimum number of activity centers for the large and small areas (10 and 6, respectively) seemed adequate for this evaluation. Regarding the selection process, some participants indicated that they looked at this task as a useful exercise to determine the centers with the highest travel demands - where people are coming from and going toand to see how well transit serves those centers. However, some indicated that the temptation would be very strong to select centers of activity already well served by the existing transit system so as to demonstrate better QOS measures. While FDOT is aware that QOS measures are not expected to be very strong statewide, at the local level, some individual agencies feel the need to look after their own interests and present their transit system in the most positive light for fear of local media gaining access to and misinterpreting the purpose and results of the TCQS evaluation. As a result, it is recommended that activity centers be reselected for each evaluation, as appropriate, to reflect new growth and travel patterns in the area. Also, it might be best for the transit systems to have less involvement in the selection of those activity centers; the MPO or an objective party should oversee the selection process. A balance between origins and destinations should also be achieved. 
2- From the O-D pairs derived according to the activity centers, the local travel demand model provides estimates of total travel demand (auto and transit) for each trip which are then ranked. Passenger Loading and Reliability QOS measures are then applied to the 15 O-D pairs with the highest travel demands. While this seems straightforward, most of the participants in this evaluation experienced moderate to extreme difficulty in determining the travel times between the activity centers (models will measure between the centers of TAZs, not point-to-point) and expressed discontent that theoretically-estimated travel demands and travel times were being compared to actual transit loads and travel times. Some participants believe that, although it would be labor-intensive, the best way to do the comparisons would be to take field observations on auto travel between the activity centers, i.e., drive the trip in an auto on the same day(s) the transit observation(s) are made. This may be unrealistic, especially given the fact that no additional resources are provided to the MPOs to conduct this evaluation, but it would allow true "apples to apples" comparisons. It may be feasible to drive a few of the trips to determine how closely the model results represent actual conditions. The travel demand models in each individual area often use different years' data, are updated on different schedules, and provide results in varying forms. Individual areas need to be aware of exactly what information the local model is providing, and must be sure that any peak and seasonal factors are applied as appropriate. Since this evaluation is primarily the MPOs' responsibility, MPO staff must take the lead in working with the travel demand model to provide the necessary information for the evaluation. In addition, as resource availability allows, participants should drive some of the trips between activity centers on the same day(s) that transit observations are made to test the validity of the model results.

3- $\quad$ Another issue deals with selection of the top 15 trips and the occurrence of both directions of movement between two activity centers in the top 15 trips. Movement between residential areas and employment centers is different between other pairs of destinations such as between an airport and a CBD or between a mall and a hospital, for example. In the first case, it might be expected that the same number of persons who travel from a residential area to an employment center would make the return trip. Directional travel demands are not always as predictable for other pairs. Nonetheless, participants were to rank all of their O-D pairs and select the 15 pairs with the highest travel demands for further measurements on passenger loading and reliability. The Agency Reporting Guide did not include any information regarding the logical application of this technique. Passenger Loading and Reliability QOS results in this report represent only the top 15 trips; others were excluded. However, several participants analyzed the resulting top 15 
O-D pairs and tweaked them to either remove one pair's direction of movement if both were included or to be sure that all activity centers were represented. The latter reason may deal more with the initial selection of activity centers if trips between some were not recognized in the top 15 pairs. Otherwise, if the top 15 trips include both directions of movement between one or more pairs, and the travel demand results are not identical, then both trips should be included in the final analysis. To ensure consistency across agencies in the state, all participants should analyze their top $15 \mathrm{O}-\mathrm{D}$ pairs according to the model results. Further exploration is needed on this issue, and should be addressed in any future update of the Agency Reporting Guide.

4- The time frame for the QOS measurements is the p.m. peak period as defined from 4:00 p.m. to 6:00 p.m. This ensures consistency with roadway traffic measurements. However, suppose one of the trips among an agency's top 15 is from a residential area to a center of employment, such as an industrial park or CBD. It is logical to assume that this trip has the highest travel demands in the a.m. peak as opposed to the p.m. peak. In such a case, the travel demand model is forecasting all-day demands without accounting for time period. One participant, which had such a trip, measured the reverse direction in the p.m. peak. This makes intuitive sense, but this problem would be eliminated if measurements could be taken in the a.m. peak, as well. Several agencies liked the idea of including the a.m. peak, noting that it is a "tighter," more concentrated period. People tend to leave for work or school during the time between 7:00 a.m. and 9:00 a.m., but the afternoon peaks tend to be much more spread out, sometimes from 3:00 p.m. to 7:00 p.m. in some areas. This is due to workers leaving their jobs early to run errands or later to take advantage of employers' flex-time opportunities, and students who are often finished with classes in the early afternoon. It is recommended that participants analyze the resulting top $15 \mathrm{O}-\mathrm{D}$ pairs and determine the time period (a.m. versus p.m. peak) during which the individual trips would be expected to have the higher travel demands. Then, the trip could be measured during the appropriate time period. If no valid determination can be made, then the measurement should default to the p.m. peak period.

5- The thresholds for passenger loading are determined using the square footage available per passenger or the number of passengers per seat on the vehicle. This accounts for standee loads and, understandably from the riders' point of view, the more crowded the vehicle, the lower the QOS measure. However, one's level of comfort with a crowded vehicle or even a standee load is usually inversely proportional to the length of the trip. To be certain, there are some individuals who would never be comfortable standing for any length of time due to physical conditions. However, for most individuals, standing for a shorter length of time can be acceptable. Further exploration is needed to determine 
whether the length of the relevant trip or segment can be incorporated into the measurements for Passenger Loading QOS.

6- $\quad$ For the purposes of obtaining passenger loading and reliability information, if a transit trip between activity centers necessitated a transfer, measurements were to be taken at the maximum load point of the first segment required for the trip. Many participants believe that this methodology did not result in a meaningful representation of the entire trip, especially if a needed transfer point was located close to the trip origin. It seems that this issue can be remedied with little additional effort on the part of those involved in the evaluations. For transit trips that include one or more transfers, it is recommended that service frequency and hours of service information be averaged over the routes required to accomplish the trips. The maximum load point along the entire trip should be determined, and then measurements for passenger loading and reliability taken on the segment that represents that maximum load point, which may not be on the first leg of the trip.

7- $\quad$ Each participating agency was to collect the field observations for passenger loading and reliability during a one-month time frame in March 2001. Several participants believe that this window of time is too short. For some, especially the systems with less service frequency, it was difficult to obtain the minimum number of observations within the given time frame due to issues with staffing. Systems with less frequent service could collect fewer observations per day and thus needed staff in the field for more days than the systems with higher peak frequencies. Particularly for those agencies that conducted the evaluation in-house, additional staff time out in the field for this purpose meant additional costs either in terms of overtime payments or in terms of less attention to other necessary tasks regularly assigned to the staff. Another issue was that, if trip observations were missed or collected incorrectly, there were often little or no other opportunities to collect the information as required in the Agency Reporting Guide. Some participants faced with this type of situation went ahead and collected the data outside the March 2001 period, while others substituted other O-D pairs outside the top 15 or simply completed the evaluation using the fewer number of observations. While the need to resample trips due to data collection error will undoubtedly decline as the TCQS process is refined and familiarity among the participants improves, it is recommended that the time frame for collecting passenger loading and reliability data be increased from the current fourweek time period to a six- or eight-week period.

8- Yet another issue to consider regarding the time frame for collecting the data pertains to the varying peak months experienced by agencies in various geographic locations 
throughout the state. While locations in central and south Florida tend to experience peak travel demands and ridership between February and April, locations in northern Florida, including the panhandle, tend to experience spikes during the summer (June, for example). It is understood that one of the intentions of this first-year effort was to examine a "snapshot" of transit performance across Florida. However, it was also the intention to measure typical weekday transit performance in the p.m. peak of the peak travel time. If it is indeed the case that FDOT wishes to measure the performance of its transit systems during peak ridership months, then participants should be able to choose the four-, six-, or eight-week time frame based upon individual agency ridership variations. Participating agencies would need to provide evidence that the selected time frame represents the ridership peak. In this case, the statewide results would be presented in terms of how well Florida's transit systems perform, overall, during their peak periods. The statewide results could be compiled at the end of a calendar or fiscal year to allow time for each participant to complete the evaluation.

9- If the recommendation to widen the window of time for the collection of field data is implemented to allow for a six- or eight-week time frame, then the requirement to collect the information only on Tuesdays, Wednesdays, or Thursdays should stand. These three days are representative of the "typical" weekday and are the days used for conducting weekday transit surveys as well as collecting traffic information. However, given the shorter four-week time period, it may be feasible to allow some systems to collect data on Mondays, as well. Several of the participants representing smaller areas indicated that their weekday ridership tends to be very flat, and that there is no statistical variation Mondays through Thursdays (and sometimes even Mondays through Fridays). These smaller areas also tend to have the less frequent transit services, necessitating additional data collection days to acquire the minimum number of observations. It is recommended that, if a participating agency can show valid data to prove that Monday ridership is not statistically different from ridership on Tuesdays, Wednesdays, or Thursdays, then that participant should be able to use Mondays to collect field data. Data collection on Fridays would not be allowable for any of the participants.

10- The reliability, or on-time performance, measurements caused problems for many of the participants. Overall, the Reliability QOS results were poor statewide. For all of the participating agencies, 55.5 percent of the observed top 15 O-D pairs were designated QOS $\mathrm{F}$, which translates to on-time performance of less than 80 percent. Approximately 51 percent of the smaller systems and 62 percent of the larger systems reported Reliability QOS F. Reasons for these results offered by participating agencies were numerous. Most indicated that transit schedules are not written for the peak periods and that "everyone" is 
always late during the peaks. Some observed that, for a bus system operating on mixedtraffic right-of-way, poor roadway LOS resulted in poor Reliability QOS since the transit vehicles must negotiate the congested traffic conditions. Also, it is often the case that a maximum load point, where measurements should be taken, occurs at a transfer center, where several buses may meet for timed transfers. Many times the transit vehicles wait for each other so if one runs late they all will be late. Another issue is when recovery time is built into a schedule so that a vehicle may arrive at a transfer center that represents a maximum load point more than five minutes early (designating it as not on-time), but will leave on schedule. Finally, participants noted that being 30 minutes late is counted the same as being 6 minutes late. Most of the time, a vehicle that is just a few minutes late can make up the time later in the run. However, if transit vehicles are routinely 15,30 , or more minutes late, then that can indicate a more serious problem. The results of the Reliability QOS measures should lead to a closer look at a system's schedules to be sure they are realistic for peak conditions. Peak versus off-peak scheduling might be considered by some. In addition, the driver of a vehicle that is running late to a timed transfer point should be encouraged to radio ahead to the other vehicles waiting at the facility (or inform dispatch) so only those who will be receiving transfers from the late route will wait while the others go ahead to keep the schedule (though practiced routinely by several systems, this is an internal procedure issue for each transit system, as are any existing service standards or guidelines regarding on-time performance).

Closer examination is needed of the threshold definitions of the Reliability QOS measure. A sliding scale may be appropriate so that a worse QOS level is associated with a greater number of minutes late. Or, an average score can be developed from the field observations to account for how many times the vehicle was late and by how many minutes. Furthermore, while transit service running "hot" (early) is never desirable, and a system's existing service guidelines or standards may include a definition of on-time performance that penalizes service that arrives or leaves too early, it is not clear that such a definition should apply for the TCQS evaluation. An analysis of the results shows that most trips that were not "on-time" were late, and those that arrived too early were at transfer centers and did not leave before the scheduled time. It is certainly not desirable from the passengers' standpoint to have transit service that leaves early from a designated stop. However, the measurements taken at the maximum load points for the purposes of the TCQS evaluation usually occurred at transfer points, major activity centers, and/or places where recovery time was built into the schedule. Transit vehicles running hot during their runs will most likely get back on schedule once they arrive at the major activity center or transfer point (i.e., maximum load point). In summary, the TCQS evaluation focuses on trips that both originate and arrive at a 
major activity center, where it is very unlikely that a transit vehicle will depart ahead of schedule.

11- Some participants in this evaluation speculated that the application of the TCQS measures to route segments between activity centers does not present a complete representation of the transit service. As described earlier in this report, participants shared their views concerning the evaluation of trip segments versus entire routes and some believe that, by using the TCQS measures to evaluate whole routes, the results would be easier to understand and would render a more accurate portrayal of system performance. It is believed by some that it is unreasonable to try and "fit" transit into a model meant for auto travel. However, other participants, realize that, to best evaluate how well transit serves the trips with the highest travel demands, it is necessary to evaluate the trip itself. As such, this report recommends that the evaluation of the transit trips between major O-D pairs continue in subsequent evaluations.

12- Results from the Service Coverage QOS analysis were difficult to interpret on a statewide level. This was due to the fact that different methodologies and data representing various years were used by the participating agencies. Only two participants used the manual method for calculating the percentage of the transit-supportive area served by transit, as opposed to the GIS method. It is hoped that these two participants will be able to take advantage of GIS capabilities in future evaluations. Regarding the data used, with the continuing release of Census 2000 data, each participant should be able to use year 2000 data for the next TCQS evaluation (only three used 2000 data in this evaluation), thus enabling easier aggregation of the results. Participating agencies should all use data representing the same year, and FDOT may even consider standardizing the geographic unit used in calculating service coverage. If every participant uses the same method and data from the same year, a valid estimation of the percentage of the transitsupportive area in the state served by public transit will be obtainable.

13- Training courses and materials were provided to the participating agencies in advance of this first-time effort. Training courses were held in November 2000, four months prior to the start of the evaluation. In addition, an Agency Reporting Guide, prepared by Kittelson and Associates, Inc., for FDOT, was provided to the participants. Staff from Kittelson and FDOT also made themselves widely available to assist the agencies in the preparation and conduct of the evaluation. Many participants had little trouble with the process and/or were pleased with the support provided. The training courses were, by all accounts, extremely helpful. However, some areas were unable to send representatives to the training, and those participants tended to encounter more difficulties during the 
evaluation, and some areas were not pleased with the level of assistance. Some of the results also indicate that further training is needed, and there are some clarifications that should be made in the written materials provided to the participants. Examples of misinterpretations of the information in the Agency Reporting Guide included the idea that a p.m. peak trip could only be included in the field observations if it could be completed by 6:00 p.m. (trips departing the origin between 4:00 p.m. and 6:00 p.m. should be counted, even if they arrive at the destination past 6:00 p.m.) and the assumption that fewer than a minimum of 10 observations could be collected for the passenger loading data (at least 10 observations were required). It is recommended that, with the experience gained by all involved with this first-time effort, additional training be held in the future, and in locations that are easy to travel to for the participants in north, central, and south Florida (e.g., Tallahassee, Tampa, Ft. Lauderdale). Also, the Agency Reporting Guide should be evaluated and updated to include new or modified procedures and a clarification of other issues.

14- Strong opinions were voiced by participants regarding the fact that no additional funds were provided to the agencies to conduct this required evaluation, particularly by transit systems that had to shoulder a larger portion of the work involved in completing this effort. Perhaps a few of the MPOs, realizing there were no new funds for this project, expected the transit systems to take on more of the tasks, resulting in the notion of "passing the buck," as expressed by one participant. Costs to conduct this evaluation ranged from "negligible" to $\$ 50,000$, with most about $\$ 4,000$ to $\$ 5,000$. Clearly, in some areas, a much higher level of resources was expended on the TCQS evaluation than should have been necessary. With proper advance planning and by taking advantage of less expensive local labor options if needed (e.g., temporary workers, local college/university students, senior citizen groups, volunteer organizations, etc.), costs should be kept at a minimum. If an area wishes to contract out to conduct the evaluation, it is expected that there will continue to be plenty of advance notice of future evaluations so that the contractual process can be completed. It is anticipated that future efforts will cost less as participants prepare earlier and become more familiar with the process, thus needing to spend fewer hours directly on TCQS tasks.

15- The Florida MPO TCQS Evaluation was intended to be an annual effort. However, it has already been determined that field data collection will not be required for the next evaluation. The reselection of activity centers on a regular basis is a useful exercise. However, given the fact that the local travel demand models are not updated annually and the fact that transit services do not typically experience significant changes from year to year, the benefits (i.e., useful information) from annual evaluations may outweigh 
the costs. Therefore, it is recommended that the TCQS Evaluation be conducted in full as part of the Long Range Transportation Plan Update Process. The reselection of activity centers and the examination of transit system performance in serving those centers bi-annually will capture major changes in travel patterns in the area and the transit system's response to those changes, even if the local travel demand model is not updated. Once a schedule for the evaluations is determined, each agency that is expected to participate should be sure to plan appropriately for the proper collection and reporting of the TQOS measures. To the extent possible, the TCQS effort should be coordinated with other data collection efforts such as the TDP or other in-house programs.

The items and recommendations presented in this report are intended to provide FDOT with an overall assessment of Florida transit performance in terms of the six TQOS measures included in the TCQSM. More importantly, this report evaluates the process of the first-year statewide implementation of these measures and summarizes the experiences of those involved. It is the objective of this report to provide FDOT and other interested parties guidance on refining the process in order to extract meaningful, useful, and valid results in the future, with minimum effort. In general, further research is needed in areas regarding the selection of O-D pairs, data collection for passenger loading and reliability, and the thresholds for the TQOS measures, particularly reliability and overall on-time performance issues. With better, consistent results, the aim of evaluating statewide transit service on an " $\mathrm{A}$ " through " $\mathrm{F}$ " scale, similar to roadway LOS, can move the state closer to the ultimate goal of increasing investment in public transit services and can serve as a model for other states with the same objectives. 